\title{
man \\ Mitigating Generation Schedule Deviation of Wind Farm Using Battery Energy Storage System
}

\author{
Asmamaw Sewnet ${ }^{1}$ D, Baseem Khan ${ }^{1}$, Issaias Gidey ${ }^{1}$, Om Prakash Mahela ${ }^{2} \mathbb{D}$, Adel El-Shahat ${ }^{3, *(\mathbb{D})}$ \\ and Almoataz Y. Abdelaziz ${ }^{4}$ (D)
}

1 Department of Electrical and Computer Engineering, Hawassa University, Awasa P.O. Box 05, Ethiopia; asme.sew405@gmail.com (A.S.); baseemkh@hu.edu.et (B.K.); isuag7@gmail.com (I.G.)

2 Power System Planning Division, Rajasthan Rajya Vidyut Prasaran Nigam Ltd., Jaipur 302001, India; pg201381003@iitj.ac.in

3 Energy Technology Program, School of Engineering Technology, Purdue University, West Lafayette, IN 47907, USA

4 Faculty of Engineering and Technology, Future University in Egypt, Cairo 41639, Egypt; almoataz.abdelaziz@fue.edu.eg

* Correspondence: asayedah@purdue.edu

check for

updates

Citation: Sewnet, A.; Khan, B.; Gidey,

I.; Mahela, O.P.; El-Shahat, A.;

Abdelaziz, A.Y. Mitigating

Generation Schedule Deviation of

Wind Farm Using Battery Energy

Storage System. Energies 2022, 15 ,

1768. https://doi.org/10.3390/

en15051768

Academic Editors: Zhiwei Liu, Feng

Liu, Ming-Feng Ge and Ming Chi

Received: 21 December 2021

Accepted: 16 February 2022

Published: 27 February 2022

Publisher's Note: MDPI stays neutral with regard to jurisdictional claims in published maps and institutional affiliations.

Copyright: (c) 2022 by the authors. Licensee MDPI, Basel, Switzerland. This article is an open access article distributed under the terms and conditions of the Creative Commons Attribution (CC BY) license (https:/ / creativecommons.org/licenses/by/ $4.0 /)$.

\begin{abstract}
Meeting the generation schedule in a wind farm is a major issue. This work utilized battery energy storage systems (BESS) integrated wind farms (WF) to supply energy to the power grid at a pre-determined generation schedule, which was set previously based on the meteorological forecast and BESS characteristics. This study proposed the integration of two independently controlled BESS into the WF to balance stochastic power deviations between actual wind power and scheduled power. By utilizing linear optimization and solving in MATLAB, simulation models of the operations of BESS-integrated WF have been developed. The technical performance of the BESS-integrated wind farm on meeting the generation schedule, along with the cost benefits and profit attributed to the BESS, is therefore measured by a series of indices. The simulation on a practical wind farm, i.e., Adama-I WF, Ethiopia shows that even though it depends on the type of state exchanging strategy adopted, the developed methodology of integrating BESS into the WF is effective and BESS profits can totally cover the cost. Technical and economic indices that resulted from the integration of two separate BESSs with independent control were compared with indices that resulted from integrating a single BESS. Simulation results show that operating the wind farm with two independently controlled batteries has better performance as compared to operating with a single battery. It also shows that the discharging and charging state exchanging approaches of the BESS (in the case of two battery integration), as well as the number of batteries integrated into the wind farm, have significant impacts on the performance of the WF integrated with BESS.
\end{abstract}

Keywords: dual battery operation; linear optimization; single-battery operation; state exchanging strategy

\section{Introduction}

\subsection{Motivation and Incitement}

Wind energy (WE), as a renewable energy, is plentiful, widely distributed, clean, and does not release greenhouse gas (GHG) during operation. Currently, it has achieved fast growth due to the rapid increase of energy demand and accelerating depletion of the world fossil fuels [1]. Recently, relatively high levels of wind power penetration have been achieved in some countries. The penetration level of Denmark has reached $48 \%$, followed by Ireland with 30\% and Portugal with 30\%, according to the report of the United States of America Department of Energy [2]. Denmark has an ambitious target of 50\% in 2020 of which around $48 \%$ wind power generation is achieved whereas the United States has planned projections of wind power capacity to be as large as $30 \%$ of total generation by 2030. WFs, unlike traditional generators, are unable to be deployed flexibly because of 
the unpredictability of wind patterns and, as a result, their intrinsic probabilistic character. As a result, network administrators must deploy extra operating reserve to deal with probabilistic wind energy in terms of maintaining the appropriate degree of grid security and dependability [3]. Furthermore, deploying greater operational reserve would almost certainly raise operating costs since so many units would be dispatched [4,5]. Meanwhile, fast advancements in battery storage have offered a potential way to deal with probabilistic wind energy $[6,7]$.

\subsection{Literature Review}

In this section, a literature review on the types of storage integrated into the wind farm, type of control strategy, number of batteries to be integrated, and benefits are discussed. Various simulation methods and profitability tests can be found in the literature in terms of both battery energy storage for stand-alone applications and in conjunction with renewable sources. A review of the relevant studies will be presented below.

In ref. [8], Oudalov et al. carried out the optimum sizing of the lead-acid BESS for primary frequency control in European markets, describing it as the most useful service for the storage device user. In ref. [9], Schweer et al. have followed a similar strategy, where the operation of the hybrid battery storage has been designed to provide frequency reserve containment. To render the built model linear, a piece-wise approximation has been utilized. In ref. [10], Korpaas et al. studied the significance of balancing the differences between the expected and actual output of WE by conducting a three-step simulation: first, wind production is projected. Second, the bids on the power exchange are scheduled based on this prediction. Finally, the function of the storage in real-time is simulated to offset the variance of the generation of WE from the expected one. Using a dynamic programming algorithm, the model was resolved, and the efficiency of the battery was established as a significant factor. In addition, results show that the storage capacity depends on the difference between the spot price and the regulatory power price. Following two primary methods, energy storage systems with arbitration purposes were simulated. The first is the setting of price triggers that permit the device to charge or discharge when reached. These prices can be static, computed from historical time series or dynamically altered using moving averages during battery operation, as stated In ref. [11]. A second alternative is to assume a price forecast and optimize the bidding strategy, such as the day-ahead bid, which maximizes potential revenue with a linear or mixed-integer linear program, as suggested by Sioshansi et al. [12] and Graves et al. [13]. The projected WE in the next hour were chosen as an electricity schedule by Teleke et al. In ref. [14]. For that purpose, a traditional feedbackdependent control technique has been developed for controlling the BESS. It enables the BESS-associated WF to produce energy according to the scheduled generation. In ref. [15], an optimal control technique based on open-loop has been developed. The feedback-based control technique produced better results in meeting the generation timetable as compared to the open-loop-based control technique, but it led to repeated switching between charging and discharging states of the BESS, thus shortening the lifetime of the BESS. Li et al. develop a new operation plan In ref. [16] to complete a full charging period followed by a discharge cycle in order to increase the lifespan of BESS. This method, however, was very complex and, as per the actual WF power production, required regular revisions. In Refs. [17,18], Yao et al. split the BESS into two parts, designated as in-service and stand-by BESS, correspondingly. Separate control is employed to regulate them. In ref. [19], Yuan et al. utilized BESSs for balancing power deviations among the WE outputs and scheduled production in order to reduce the BESS capability requirement. In ref. [20], optimal maintenance planning and resource allocation for wind farms based on a non-dominated sorting genetic algorithm are presented. In ref. [21], scheduling of electric vehicle charging to minimize carbon emissions and wind curtailment is presented. In ref. [22], a novel control strategy for enhancing microgrid operation connected to photovoltaic generation and energy storage systems is described. In ref. [23], a techno-economic assessment of energy storage systems using annualized life cycle cost of storage (LCCOS) and levelized cost of energy (LCOE) 
metrics is performed. A robust energy management and economic analysis of microgrids considering different battery characteristics is presented In ref. [24]. In ref. [25], optimal planning and operation of energy storage systems for minimizing the cost of energy losses and maximizing arbitrage benefits in the presence of wind generation are performed. In ref. [26], the grey wolf optimizer is utilized for optimal sizing and siting of energy storage systems in electric distribution networks. The authors of ref. [27] discussed a machineintelligence-based forecasting-based technique for penalty cost minimization in hybrid wind-battery farms. In ref. [28], wind turbine gearbox anomaly detection is performed, which is based on adaptive threshold and twin support vector machines. In ref. [29], wake management-based life enhancement of battery energy storage systems is performed for hybrid wind farms. For hybrid wind farms, ref. [30] employs a fuzzy technique for order preference based on similarities to the ideal solution (TOPSIS) and a fuzzy complex proportional assessment (COPRAS) based multi-criteria decision-making approach. In ref. [31], hybrid machine intelligent support vector regression (SVR) variants are utilized for wind forecasting and ramp events. In ref. [32], the authors proposed an optimization technique for battery energy storage with wind turbine generator integration into an unbalanced radial distribution network. In ref. [33], techno-economic optimization of battery storage for grid-level energy services using curtailed energy from wind is performed. In ref. [34], authors presented the utilization of energy storage systems for enhancing the distributed generation connections and network operations on the Shetland Islands. In ref. [35], sizing and coordination strategies of battery energy storage systems co-located with wind farms are presented in relation to the United Kingdom perspective. In ref. [36], a dynamic analysis of energy storage with renewable and diesel generation using volterra equations is presented. In ref. [37], an adaptive neuro-fuzzy inference system (ANFIS) based peak power shaving/curtailment method in microgrids including photovoltaic units and battery energy storage systems is proposed. In ref. [38], authors presented a joint market bid methodology for a hydroelectric system and wind parks. In ref. [39], authors presented the generation schedule tracking of wind farms with battery energy storage systems. In ref. [40], enhanced emulated inertia control for grid-connected photo-voltaic systems with hybrid energy storage systems in a weak grid is presented by the authors.

\subsection{Research Gap}

By reviewing different research papers, it is concluded that different researchers utilize the BESS system with various available control techniques, such as fuzzy systems, the ANFIS method, and support vector mechanisms. All these methods are complex as training and formulation of the various rules are required. As compared to the abovediscussed techniques, the proposed work develops the different operating strategies with linear optimization, which has less complexity and provides better results. Further, the proposed work is implemented on the practical system (Adama I), so it can provide the critical recommendations on the practical implementation of the proposed technology. Furthermore, the economic aspects attributed to the BESS, such as advantages, expenses, and income, which are not covered by the discussed literature, are incorporated in this work because batteries are so costly. Therefore, it is of great importance to consider the economic characteristics of the BESS.

\subsection{Contribution of the Manuscript}

This paper utilized BESSs integrated into WFs for smoothing WE fluctuation and meeting the desired generation schedules. The major contributions to this work are as follows:

- This work determined the characteristics of a storage system that have the greatest effect on its ability to mitigate fluctuations. For that purpose, the authors assessed BESS's coordination with the load flexibility. Furthermore, single-battery operation was compared to two-battery operation. 
- This research analyzed the impact of battery size and charging/discharging strategy on system economy and reliability. Furthermore, they assessed the economic value of the BESS option.

- A dual battery operation with two state exchanging strategies, i.e., simultaneous and asynchronous state exchanging strategies, is proposed. Moreover, the effects of stateexchanging strategies on the performance of BESS-integrated WFs were investigated.

- The proposed work is implemented on the practical ADAMA I wind farm, Ethiopia, based on the real data obtained from the system.

- The proposed work can provide critical recommendations and in-depth knowledge for the practical implementation of the proposed technology in a real-world system.

\subsection{Organization of the Manuscript}

The manuscript is organized as follows: Section two discussed the methodology of the proposed work. Different concepts utilized in this work are discussed in the methodology section. Section three discussed the results under various operating conditions. Section four discussed the conclusion of the manuscript.

\section{Methodology}

The methodology of the thesis report shows the technical approach of the study. The study was conducted according to the lines of the flowchart presented in Figure 1. A detailed literature review was initially conducted on Lithium-ion (Li-ion) batteries, their technical characteristics, and forms based on their chemistry and applications. The most interesting type of BESS, i.e., Li-ion battery, is selected after a thorough study and then selected to be modeled.

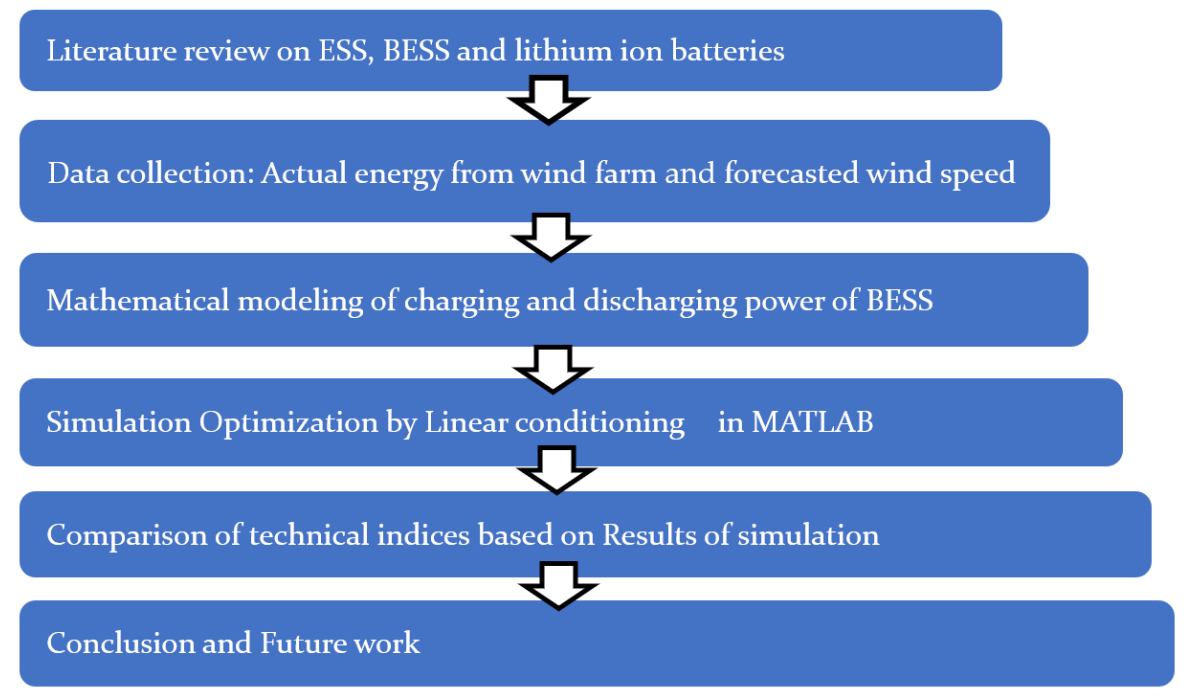

Figure 1. Flow chart of the methodology.

The next step was collecting wind speed forecast data from the Windfinder app (WINDFINDER app version 4. Available online: https:/ / www.windfinder.com/about/ history-press.htm (accessed on 14 November 2021)) (3.23.1, Windfinder, Boltenhagener, Germany) within $3 \mathrm{~h}$ of the actual wind power generation. It is possible to make a forecast even one day in advance. However, if the forecasted span increases, forecasting errors will also increase, which affects the performance of wind farms. Then the actual wind power record for the corresponding time span was taken from the wind farm. Linear optimization or mathematical control techniques are then built to perform the battery's operations and measure the possible revenue for different battery sizes. Microsoft Excel 2013 (2013, Microsoft, Albuquerque, NM, USA) and MATLAB 2019 (2019, MathWorks, Natick, MA, USA) are used for designing and solving these models. The revenue sources, 
number of cycles, and battery size are computed after computing the function of the battery for the service. An economic evaluation is carried out using these data, along with BESS investment costs and certain technological characteristics such as cycle life as inputs. The economic evaluation is then accompanied by a technical review aimed at providing some insight into the most important parameters affecting BESS profitability and break-even costs for non-profitable services.

\subsection{Wind Energy Development in Ethiopia}

Large-scale wind turbines are incorporated into the Ethiopian Energy Grid [4]. This will lead to an increase in the penetration of wind energy into the grid, and this increase will have a huge effect on the reliability of the power system unless some kind of flexibility is added. Nowadays, energy storage systems are quite comfortable being integrated with wind farms to add extra flexibility to the wind farm.

Presently, four large scale wind farms are connected to the Ethiopian gird. These are Adama-I (with installed capacity $51 \mathrm{MW}$ ), Adama-II (with installed capacity $153 \mathrm{MW}$ ), Ashegoda (with installed capacity $120 \mathrm{MW}$ ) and Ayisha-I (with installed capacity $120 \mathrm{MW}$ ). The Ethiopian electric power is continuously working to achieve the target. In addition to the above discussed four wind farms, the fifth wind farm, Ayisha-II, with installed capacity $120 \mathrm{MW}$ is also under construction.

With the use of technology witnessing rapid growth in recent years, wind energy is considered one of the most promising renewable energy resources [5]. As a result, by 2020, Ethiopia aims to increase its wind power capacity to $5200 \mathrm{MW}$. As a result, wind penetration in the Ethiopian Electric Power (EEP) will soon increase, which means that many problems such as optimal generation scheduling, low and high voltage ride-through capabilities enhancement, power quality issues will be faced by the grid due to the fact that power from the wind cannot be controlled; it is a non-dispatchable resource.

Like other generation units, WFs directly decide their short-term generation schedules in future hours and send them to the dispatch center. The dispatch center determines the power balance between supply and demand based on this time schedule [6].

However, unlike other generation units, because of the variability of the wind velocity and therefore the inherent stochastic design, WFs cannot generate flexibly. This means that when the wind unexpectedly picks up in this area, in a matter of hours, wind power generation will go from nearly 0 to $51 \mathrm{MW}$, as the installed capacity of the ADAMA-I wind farm is $51 \mathrm{MW}$. Since both power generation and consumption take place at the same moment, any balanced power system must be able to align power consumption with power generation, which means that in this case, it is difficult to reduce or increase up to $51 \mathrm{MW}$ of generation somewhere else (usually hydro units) on the system in a short time. Therefore, to ensure the necessary degree of protection and reliability, it needs extra flexibility from the power system [7].

\subsection{Existing System Description}

Adama-I wind farm, Ethiopia, has 34 turbines with a combined capacity of $51 \mathrm{MW}$. The turbines are arranged in three groups and submit their generated power to the substation through a step-up transformer and switch gear. Then this power is directly injected into the grid through a step-up transformer $(33 / 132 \mathrm{kV})$. The power schedule and actual generated power are shown in Figure 2 below. As shown in Figure 2, the actual power always fluctuates around the forecasted value. As explained in the literature, it is this unpredictable and fluctuating nature of actual power that causes a power mismatch between generation and demand. So, the wind farm should add some flexibility to its generation system so that actual power will match the pre-determined schedule. To do this, three possible options were mentioned in the literature, namely: gas generators, curtailment, and energy storage systems. As discussed in the previous section, BESS was found to be the best match to fill the missing element of wind farms, i.e., flexibility. 


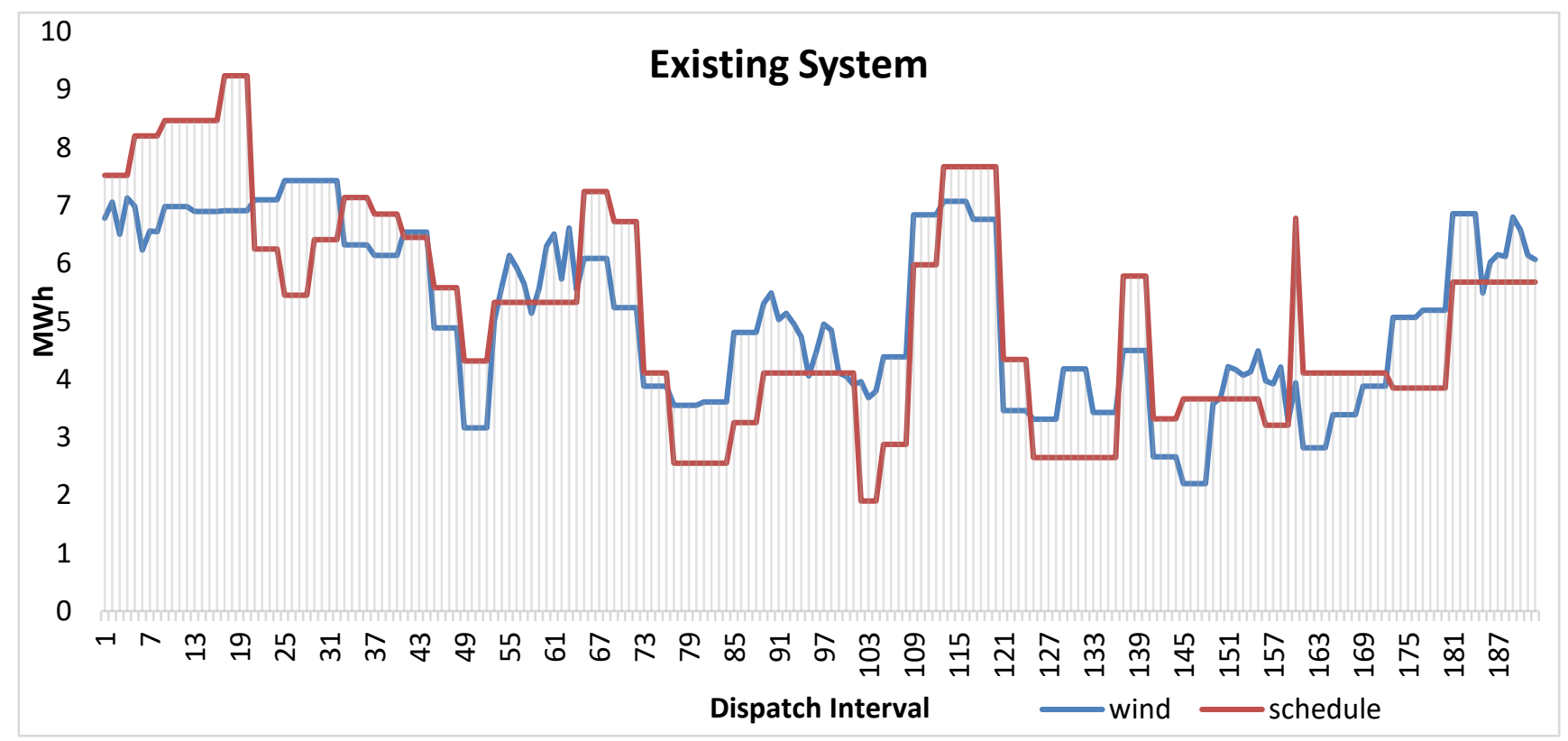

Figure 2. Output and schedule of the wind farm on a particular day.

\subsection{Utilized System Model}

\subsubsection{Model of BESS Integrated Wind Farm}

In this section, the model that was developed in this study will be described. A simplified model of the system is employed to establish the optimal operating strategy for wind power in combination with battery storage. Figure 3 below shows a scheme of the underlying system: Wind turbines and battery storage systems are connected to each other and to the grid through a common bus bar. As shown in Figure 3, the BESS is classified into two sections, namely, BESS I and BESS II, and it is integrated with the help of a DC/AC power converter.

$$
P_{W+B E S S}=P_{W}+P_{b}
$$

where, $P_{W}$ represent the output the WF, $P_{b}$ is the charging/discharging power of the BESS, $P_{W+B E S S}$ is the output of the BESS associated WF. $P_{b}$ is defined as $P_{b}=P_{b 1}+P_{b 2}$.

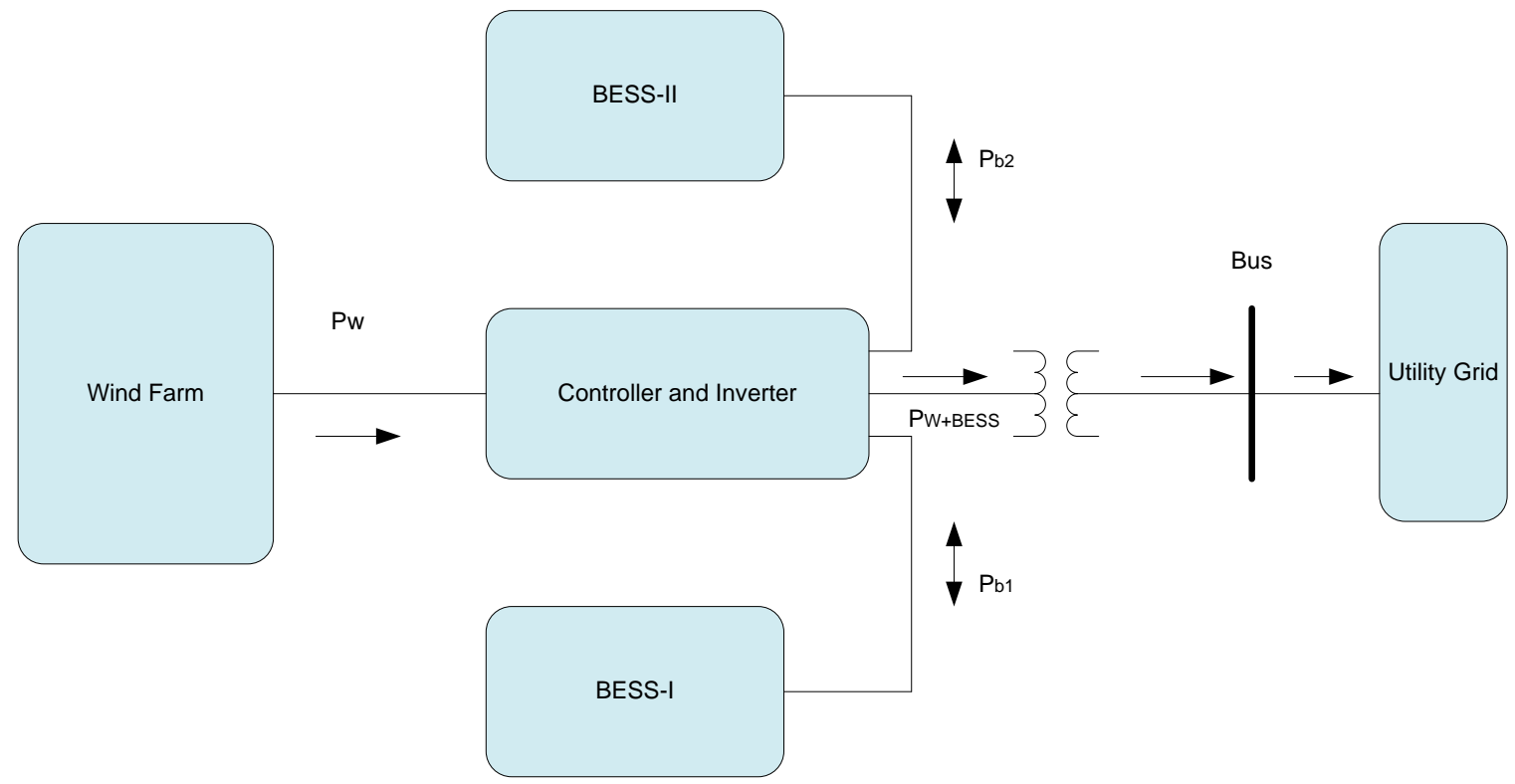

Figure 3. Schematic diagram of the BESS-associated WF. 
The reference directions of electric power flow are shown by the arrows. If the BESS is discharged, the value of $P_{b}$ is positive, while it is charged then $P_{b}$ is negative.

The addition of the BESS improves the capacity of the WF to control power, thus allowing operators to control the BESS charging and discharge power to offset probabilistic power deviations between the power output and the scheduled power. In turn, this will allow the BESS-associated WF to produce energy to some extent following the predetermined generation schedules. The BESS-associated WF is utilized to comply with the generation schedules up to this stage.

\subsubsection{BESS Control Scheme}

Figure 3 shows the role of BESS in compensating for the wind farm's irregularly varying power generation. The two batteries are linked to the WF's output and net power is injected into the device. Thus, the goal of the controller is to achieve the objective of equating the net power supplied to the grid $\left(P_{W+B E S S}\right)$ with predetermined schedule $\left(P_{S}\right)$ over a given time period. Taking $P_{S}, P_{W}$ and state of charge (SOC) as input, and keeping the constraints in mind, the controller compares the $P_{W}$ with reference $P_{S}$ and makes the decisions of which battery will charge or discharge at a time and what amount of power to be charged or discharged in each battery in order to supply the grid as per schedule.

\subsubsection{Objective Function}

Optimization aims at maximizing profit and minimizing the difference between scheduled and injected energy by managing the overall power output of the system. This output management includes direct output of the wind turbines to the grid as well as charging the battery with WE and discharging it into the grid. The objective function and constraints, along with parameters and decision variables, are as follows.

The objective function is derived from the optimization statement above and is formulated in the following equations [36,39].

$$
M_{\text {in }}=w_{1}\left(P_{W+B E S S}\right) T-w_{2} \times P_{d i v, i} * T
$$

where,

$$
P_{\text {div }, i}=\left|P_{s, i}-P_{w+B E S S, i}\right|
$$

where, $P_{\text {div }, i}$ represents difference between scheduled power and output power of the BESS-integrated WF, $M_{i n}$ is the BESS associated WF's income, $w_{1}$ represents tariff of the existing system while $w_{2}$ represents the tariff when the BESS-integrated WF is fined due to the power deviations, and $\mathrm{T}$ represents duration in hours.

This work reduced the power deviation from the schedule so the grid would get as per schedule and to maximize the benefit as much as possible.

\subsubsection{Constraints}

Constraints are used to maintain the maximum physically possible power flow. The work of BESS-associated WF is constrained to the following conditions:

\section{Battery Capacity}

Initially assume that at dispatching Interval (DI $i$ ), active power generated from $\mathrm{WF}\left(P_{W, i}\right)$ is greater than the preferred schedule provided to dispatch center $\left(P_{s, i}\right)$, i.e., the power deviation between $P_{W, i}$ and $P_{s, i}$, is greater than zero. In order to ensure that the BESS-integrated WF produces power at the preferred schedule for energy production, the excess power that is supposed to be in the charging state must charge BESS I, otherwise, this part of the energy should be reduced. Equation (4) can be used in this case to calculate the maximum permissible charging power given by BESS I at DI $i$ [36,39].

$$
P_{m c I, i}=-\max \left\{0.5 P_{r, c h} E_{c},\left[0.5\left(S_{\max }-S_{I, i-1}\right) E_{c}\right] /\left[T \eta_{c h}\right]\right\}
$$


The capacity of BESS I is $0.5 \times E_{c}$, where, $E_{c}$ is the capacity BESS, $S_{\max }$ is the maximum allowable value of battery SOC, $S_{1, i-1}$ is $S O C$ of BESS I at DI $i, P_{r, c h}$ is the rated charging power of the BESS with unit capacity, $\eta_{c h}$ is used to roughly represent the internal losses in batteries and converters, at charged condition.

Assume $P_{W, i}$, is lesser than the $P_{s, i}$. For compensating the deficiency of power, BESS II, should be discharged; if not, the BESS associated WF will not generate the equal value of power as required meeting the schedule of generation. Equation (5) will specify the maximum permissible discharge power given by BESS II at DI $i[36,39]$.

$$
P_{m d I I, i}=\max \left\{0.5 P_{r, d i s} E_{c},\left[0.5\left(S_{I I, i-1}-S_{\text {min }}\right) \eta_{d i s} E_{c}\right] / T\right\}
$$

where, $\eta_{\text {dis }}$ represents discharging efficacy of BESS, $P_{r, d i s}$ is rated discharging power of the BESS with unit capacity, $S_{I I, i-1}$ is SOC of BESS II at DI $i$, and $S_{\min }$ is minimum allowable value of battery state-of-charge.

Battery's State of Charge

The state of charge of the battery should be within the minimum and maximum SOC limits of the battery.

$$
S_{\min }<S O C<S_{\max }
$$

\section{Profit of WF}

Even though it is not decided by the controller, the profit of WF should be considered a constraint since it prevents us from using the large battery capacity.

\subsubsection{Determination of Short-Term Generation Schedules}

The WF is assumed to take a short-term wind speed prediction from the Windfinder app, which offers wind forecasts for over 45,000 places all over the world, $3 \mathrm{~h}$ to 7 days ahead. Here $3 \mathrm{~h}$ is the time frame for which the wind forecasting is performed using the Windfinder app.

In a deregulated power structure, if WFs are unable to comply with the generation schedules submitted, the ISO will penalize them according to the power differences between the generation schedules submitted and the actual production schedule [36]. However, Ethiopian electric power is a state monopoly, i.e., all generation, transmission, and distribution systems are owned by the state. Hence, the wind farm will not be penalized even if there is a power deviation from the submitted schedule. However, the power deviation will cause a mismatch between the load and generation, which will reduce distribution system reliability and maximize customer dissatisfaction [39].

The essence of the meeting generation plan for the BESS-integrated WF is to use the BESS to reduce power deviations between actual and scheduled generated power. The predicted charging energy $\left(E_{c h}\right)$ at DI is expressed by the following equation $[36,39]$.

$$
E_{c h}=\int_{P_{s}}^{1} f(x)\left(x-P_{s}\right) T d x
$$

where, $P_{S}$ is submitted power generation schedule, $x$ is the stochastic variable that denotes per unit value of wind power in the versatile distribution. Further, $f(x)$ represented the probabilistic density function (PDF) of the variable nature of the wind energy, while $F(x)$ represented the cumulative distribution function (CDF) which is given as [36,39]:

$$
\begin{gathered}
f(x)=\alpha \beta \exp [-\alpha(x-\gamma)] /\{1+\exp [-\alpha(x-\gamma)]\}^{\beta+1} \\
F(x)=\{1+\exp [-\alpha(x-\gamma)]\}^{-\beta}
\end{gathered}
$$

where, $\alpha, \beta, \gamma$ are the shape parameters of the variable wind energy distribution function. 
Similarly, the estimated discharge energy at DI is determined by the following equation $[36,39]$,

$$
E_{d i s}=\int_{0}^{P_{s}} f(x)\left(P_{s}-x\right) T d x
$$

Here $T$ is generally selected as $15 \mathrm{~min}$.

A parameter of battery efficiency can calculate the ratio between discharging and charging capacity. Equation (10) presented the preferred schedule of energy production of the BESS associated WF $\left(g\left(P_{S}\right)\right)$ for achieving an equilibrium amid discharging and charging [36,39].

$$
g\left(P_{S}\right)=E_{\text {dis }}-\eta_{B E S S} E_{c h}=0
$$

where, $\eta_{B E S S}$ is the parameter of the battery efficiency.

\subsubsection{BESS Operation Strategies}

Figure 2 presents the optimal schedule of energy production for $48 \mathrm{~h}$. As seen on the power curve, the actual wind energy generation often deviates arbitrarily from the scheduled generation. Equation (11) will measure the power deviation $\left(\Delta P_{i}\right)$ among the actual $\left(P_{W, i}\right)$ and scheduled generation $\left(P_{s, i}\right)$ at DI $i[36,39]$.

$$
\Delta P_{i}=P_{W, i}-P_{s, i}
$$

If the BESS is regulated as a whole, spontaneous wind power fluctuations can lead to regular adjustments between the states of charge and discharge and can therefore significantly shorten the BESS's life. The BESS is divided into two sections of equal ability to extend the battery life. Both the sections are separately managed to balance the deviations, as shown in Figure $2[36,39]$. Two diverse state exchange strategies, called simultaneous and asynchronous state exchange strategies, are proposed to handle those two batteries, as seen in Figures 4 and 5, respectively.

\section{discharge period}

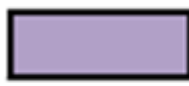

charge period

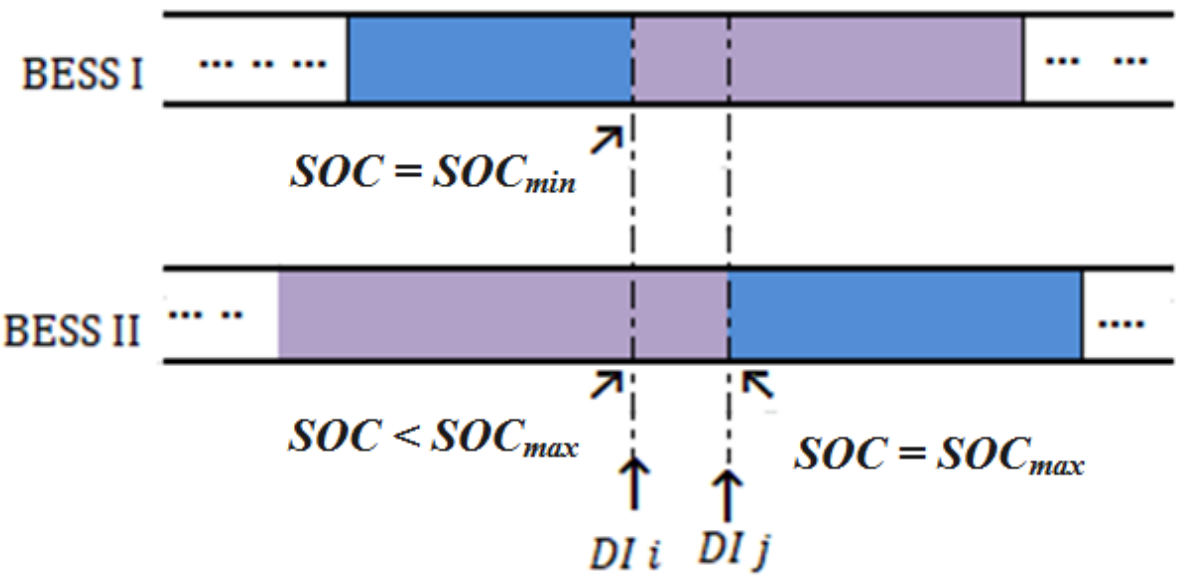

Figure 4. BESS's asynchronous state exchange strategy [39].

In Figure 4, BESS-I is presumed to arrive at DI $i$ in its completely discharged condition, i.e., the state of charge of this portion achieves its lowest permissible value $\left(S O C_{\min }\right)$. If BESS is not overcharged, it must immediately switch from discharging to charging mode. However, BESS II has not achieved its fully charged status at this time, i.e., its SOC is still below the maximum allowed amount, so it will continue charging until it reaches the maximum limit. If BESS II is not exchanged at the same time from the charge to the discharge state, two sections of the BESS are in charge condition in some subsequent DIs, i.e., 
from DI $i$ to DI $j$, as shown in Figure 4. Possible power deficiencies cannot be compensated for during these DIs as both sections of the BESS are in charge condition and can reduce output on the desired schedule. As shown in Figure 4, the BESS state strategy for exchange and the asynchronous state exchange strategy is identified.

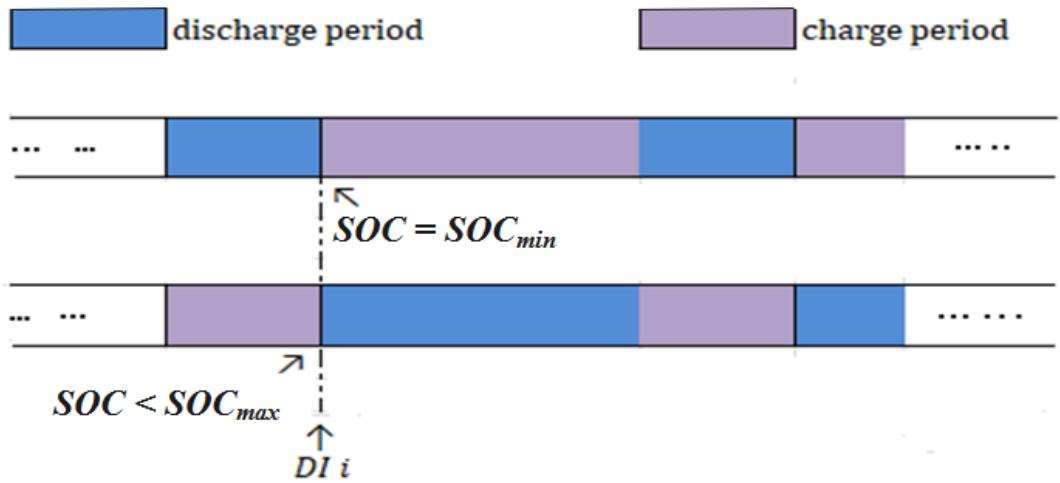

Figure 5. BESS's simultaneous state exchange strategy [39].

On the other hand, in the same case, if BESS II is exchanged from the state of charge to the state of discharge in accordance with BESS I, irrespective of the BESS II SOC (whether or not it is fully charged), the two sections of BESS are constantly at any time in reverse states. Because of this, both positive and negative deviations can be minimized to some extent by the BESS charging and discharging power. Thus, the quality of meeting the generation timetable can be significantly increased. Unfortunately, due to an incomplete discharge mechanism and consequently increasing BESS operational costs, simultaneous state exchange strategies cannot completely use BESS II (in this case). The BESS state exchange policy, shown in Figure 5, is referred to as the simultaneous technique for state exchange.

As illustrated in Figure 5, BESS II is the one that passively changes its condition to keep pace with the exchange of state with BESS I. Further, based on the random power deviations, the BESS changes its condition passively from BESS II to BESS I. As a result, in this state exchange strategy, the number of charge and discharge cycles of both parts within a specified time frame would be significantly enhanced.

\section{Charging/Discharging Power Determination}

BESS (simultaneous or asynchronous) state exchange strategies, as mentioned above, can affect BESS I and BESS II charging and discharge states. Thus, when different strategies are implemented, the BESS charging and discharging power differ.

\section{A. The simultaneous state exchanging strategy}

When the simultaneous state exchange strategy is implemented, BESS I and BESS II remain in opposite states. So, if BESS I is assumed to be the charging phase at DI $i$, BESS II going to be in discharging phase at the same time instant. At DI $i, P_{W, i}$, is greater than the $P_{s, i}$, then $[36,39]$,

$$
P_{b I, i}=\left\{\begin{array}{c|c|}
-\Delta P_{i} & \left|\Delta P_{i}\right| \leq\left|P_{m c I, i}\right| \\
P_{m c I, i} & \left|\Delta P_{i}\right|>\left|P_{m c I, i}\right|
\end{array}\right.
$$

It is evident from Equation (12) that if the deviation in power is greater as compared to the maximum permissible charging power given by BESS I, and BESS I cannot completely absorb surplus wind energy, in this case, in order to maintain the dedicated power schedule rigidly, a part of WE must be decreased. The reduced wind power can thus be defined by Equation (13) [36,39].

$$
P_{w c, i}=\left\{\begin{array}{c}
0\left|\Delta P_{i}\right| \leq\left|P_{m c I, i}\right| \\
\Delta P_{i}-P_{m c I, i}\left|\Delta P_{i}\right|>\left|P_{m c I, i}\right|
\end{array}\right.
$$


The BESS II charging power is placed to zero even though excess wind energy cannot be completely stored by BESS I. Otherwise the BESS II life would be shortened. Equation (13) will convey the supplied energy of the BESS-associated WF at this DI $i[36,39]$.

$$
P_{W+B E S S, i}=P_{W, i}+P_{b I, i}+P_{b I I, i}-P_{w c, i}
$$

where, $P_{W, i}$ is real wind power at DI $i, P_{b I, i}$ and $P_{b I I, i}$ are the charging/discharging powers of BESS I and BESS II at DI $i, P_{w c, i}$ is the curtailed wind power at DI $i$.

On the other hand, assumed the value of $P_{W, i}$ is as compared to the $P_{s, i}$, therefore, $\Delta P_{i}$ is negative at this DI. In order to fill this deficiency between the two, BESS II, which is expected to be in a state of discharge, should be discharged. Then, Equation (15) will determine the discharge power of BESS II at DI $i[36,39]$.

$$
P_{b I I, i}=\left\{\begin{array}{c}
-\Delta P_{i}\left|\Delta P_{i}\right| \leq\left|P_{m d I I, i}\right| \\
P_{m d I I, i}\left|\Delta P_{i}\right|>\left|P_{m d I I, i}\right|
\end{array}\right.
$$

If the power deviation is fewer as compared to the highest permissible discharge power supplied by BESS II, its discharge power can fully supply for the deficit. On the other hand, the WF's power output (the combined battery and wind power) would be lower than the optimal generation schedule if the power deviation is greater, meaning that there will be a lack of power on the distribution side. Therefore, at this DI, BESS I's discharge power is put to zero, although BESS II is unable to fully compensate for the power deviation. Otherwise, the BESS I Life Circle would be shortened. Assuming that the energies of discharge and charge are positive and negative respectively, the power injected by the WF can be determined by Equation (16) at this DI $i[36,39]$.

$$
P_{\mathrm{W}+B E S S, i}=P_{\mathrm{W}, i}+P_{b I, i}+P_{b I I, i}
$$

In this work, $\eta_{c h}$ and $\eta_{\text {dis }}$ are considered to be constant and equal. The following equation shows the relation between $\eta_{c h}$ and $\eta_{\text {dis }}$ in terms of $\eta_{B E S S}[36,39]$.

$$
\eta_{B E S S}=\eta_{c h} \times \eta_{\text {dis }}
$$

Figure 6 shows the algorithm of the controller to determine the battery to be used at a time with the required charged and discharged amount of energy.

The flowchart in Figure 6 shows how the charging and discharging decisions are made. The following two logics are used for this purpose:

1. At the start, it compares Es (scheduled energy) with E_ac (actual generated energy). If Es is the same as actual energy, then there will be no charging and discharging.

2. If Es and E_ac are not the same, it will go to check whether Es is greater or less than

E_ac. If Es is greater than E_ac, then some energy will be needed from the batteries.

So, it will first check the battery to see if it is ready to discharge.

After selecting the battery, it will determine the amount of energy required from the battery.

B. The state exchanging strategy for asynchronous operation

In asynchronous operation, both the BESS I and II will be in a similar state of charge or discharge over the same period of time. In this strategy, two parts of the BESS might be at the same charging or discharging state during the same periods of time. In these periods, the determination of charging/discharging power of the BESS will be different from simultaneous state exchanging strategy. In other periods during which two parts of the BESS are in opposite states, the charging/discharging power of the BESS can be determined according to the methodology proposed previously.

At $\mathrm{DI} i$, the wind power is assumed to exceed the appropriate power schedule, i.e., at this DI, the power deviation $\Delta P_{i}$ is positive. At this stage, in order to reduce wind power declines, the excess will be retained in the battery energy storage system. When two 
sections of the battery energy storage system are in the discharge condition, they can't be moved into the charging mode to save the excess WE until they are completely discharged. There will otherwise be a shortened life span of the battery. Under this condition, the whole surplus must be reduced and minimized. It can be expressed using Equation (18) in order to enable the WF to fulfill the preferred generation plan $[36,39]$.

$$
P_{w c, i}=P_{w, i}-P_{s, i}=\Delta P_{i}
$$

On the other side, if section BESS I and BESS II are paid, they both have the capacity for storing the excess WE. Equation (4) could be the maximum permissible charging power provided by them. The value of $S_{1, i-1}$ is presumed to be greater as compared to $S_{2, i-1}$, i.e., BESS I is near than BESS II to its maximum charging condition.

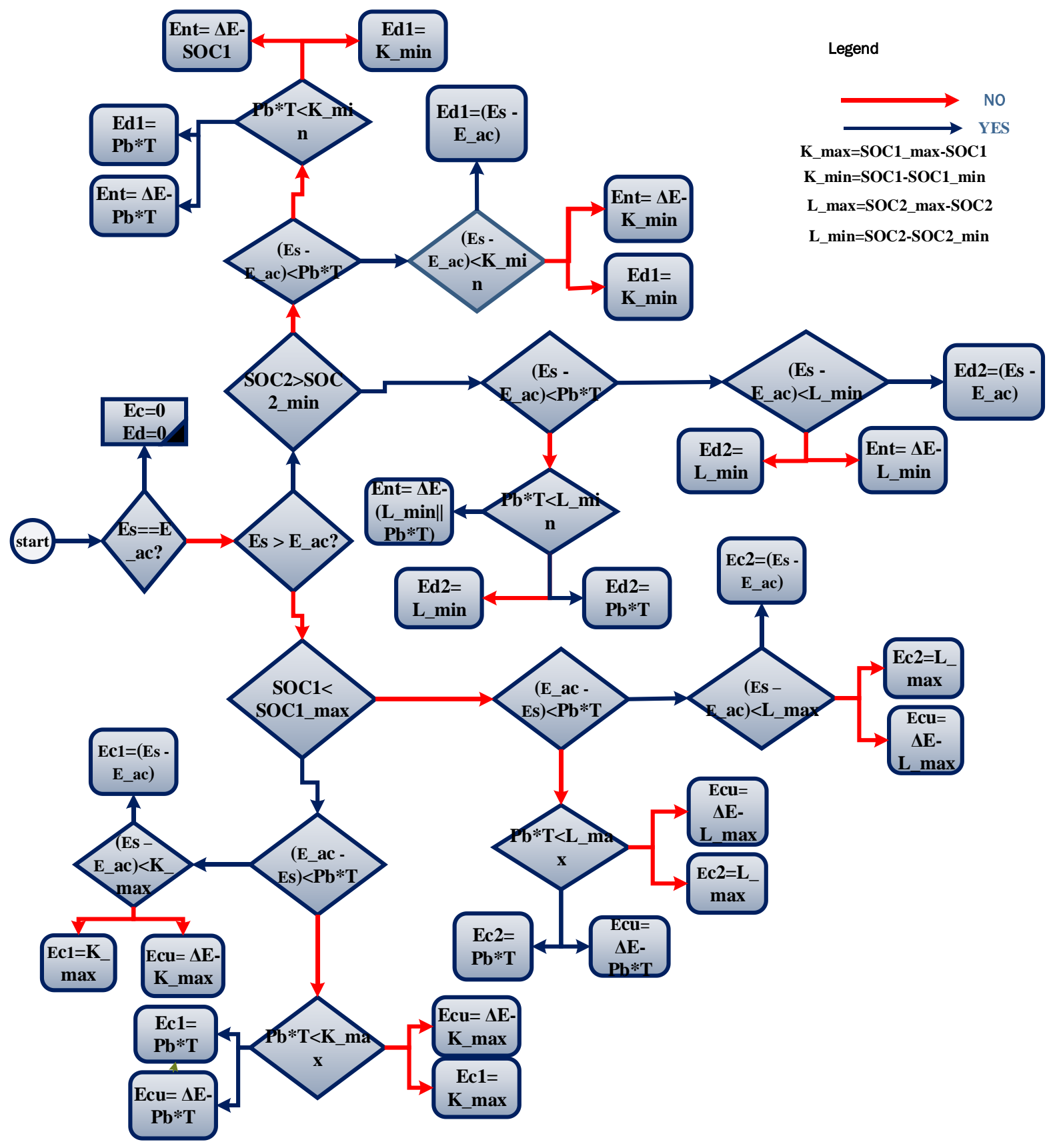

Figure 6. Control algorithm of simultaneous state exchanging strategy. 
Therefore, the priority of BESS I is to save the excess power in order that it can enter a completely charged condition as quickly as possible and move directly from the present condition of charge to the position of discharge. The WF would therefore have the capacity to match potential energy shortages. If this surplus energy is greater than the capacity of BESS I, i.e., BESS I has not fully absorbed the surplus wind energy, the surplus energy will be retained in BESS II. If the excess WE is too high to be fully stored by both battery energy storage sections, it is appropriate to minimize the remaining wind energy. In this case, the power of charging and reduced WP at DI $i$ can be expressed by the following equations $[36,39]$ :

$$
\begin{aligned}
& P_{b I, i}=\left\{\begin{array}{c}
-\Delta P_{i}\left|\Delta P_{i}\right| \leq\left|P_{m c I, i}\right| \\
P_{m c I, i}\left|\Delta P_{i}\right|>\left|P_{m c I, i}\right|
\end{array}\right. \\
& P_{b I I, i}=\left\{\begin{array}{c}
0\left|\Delta P_{i}\right| \leq\left|P_{m c I, i}\right| \\
-\Delta P_{i}-P_{m c I, i}\left|P_{m c I, i}\right|<\left|\Delta P_{i}\right| \leq\left|P_{m c I, i}+P_{m c I I, i}\right| \\
P_{m c I I, i}\left|\Delta P_{i}\right|>\left|P_{m c I, i}+P_{m c I I, i}\right|
\end{array}\right. \\
& P_{w c, i}=\left\{\begin{array}{c}
0\left|\Delta P_{i}\right| \leq\left|P_{m c I, i}+P_{m c I I, i}\right| \\
\Delta P_{i}+P_{m c I, i}+P_{m c I I, i}\left|\Delta P_{i}\right|>\left|P_{m c I, i}+P_{m c I I, i}\right|
\end{array}\right.
\end{aligned}
$$

If the WF is unable to produce sufficient energy to comply with the prescribed generation plan, then BESS stored energy should compensate for the power deficiency. There are three potential choices for state BESSs at that time.

- If the batteries are in the opposite states, i.e., one is in a charging state and the other is in a discharging state, the BESS that is in a discharging state will fill the power deficiency.

- If both the sections of the battery energy storage system are in charging conditions, they will not fill the necessary gap. In such a situation, the WF is unable to produce the amount of electricity to meet the schedule, and the supplied power represents real wind power.

- If both the sections of the battery energy storage system are in discharging conditions, the contained energy in them can discharge to minimize or even fully cover the power deficiencies. At this point, Equation (5) can be used to express the maximum permissible discharge power given by them.

As mentioned in the charging case, the discharge priority for the two sections of the BESS depends on the state of the charge. For ease of definition, it is presumed that BESS I is nearer to its full discharge condition than its counterpart. Therefore, the aim of BESS I is to discharge the saved energy in such a way that it enters into a completely discharged condition very rapidly. Then, if it reaches its fully discharged condition, once surplus is required to be stored, it will change from its present discharging condition to a charging condition. If the required power difference is not fully filled by the BESS I, the BESS II will also discharge to meet the scheduled generation. If the deficit is too high to be adequately covered by the battery energy storage system, WF operators will be out of power at this DI. In this case, Equations (22) and (23) can be used to express the discharge power of both the battery sections and Equation (15) can be used to obtain the injection power of the BESS-integrated WF [36,39].

$$
\begin{gathered}
P_{b I, i}=\left\{\begin{array}{c}
-\Delta P_{i}\left|\Delta P_{i}\right| \leq\left|P_{m d I, i}\right| \\
P_{m d I, i}\left|\Delta P_{i}\right|>\left|P_{m d I, i}\right|
\end{array}\right. \\
P_{b I I, i}=\left\{\begin{array}{c}
0\left|\Delta P_{i}\right| \leq\left|P_{m d I, i}\right| \\
-\Delta P_{i}-P_{m d I, i}\left|P_{m d I, i}\right|<\left|\Delta P_{i}\right| \leq\left|P_{m d I, i}+P_{m d I I, i}\right| \\
P_{m d I I, i}\left|\Delta P_{i}\right|>\left|P_{m d I, i}+P_{m d I I, i}\right|
\end{array}\right.
\end{gathered}
$$

Generally, scheduled energy can be obtained by a combination of the wind turbine output and the batteries; i.e., if the actual output is greater than the schedule, excess energy will be stored in the batteries, and if it is deficient, energy will be discharged from the batteries. The algorithm of the controller to determine the battery to be used at a time and 
the amount of energy required to charge and discharge the battery is shown in Figure 7.

This shows the control algorithm of the asynchronous state exchanging strategy [36,39].

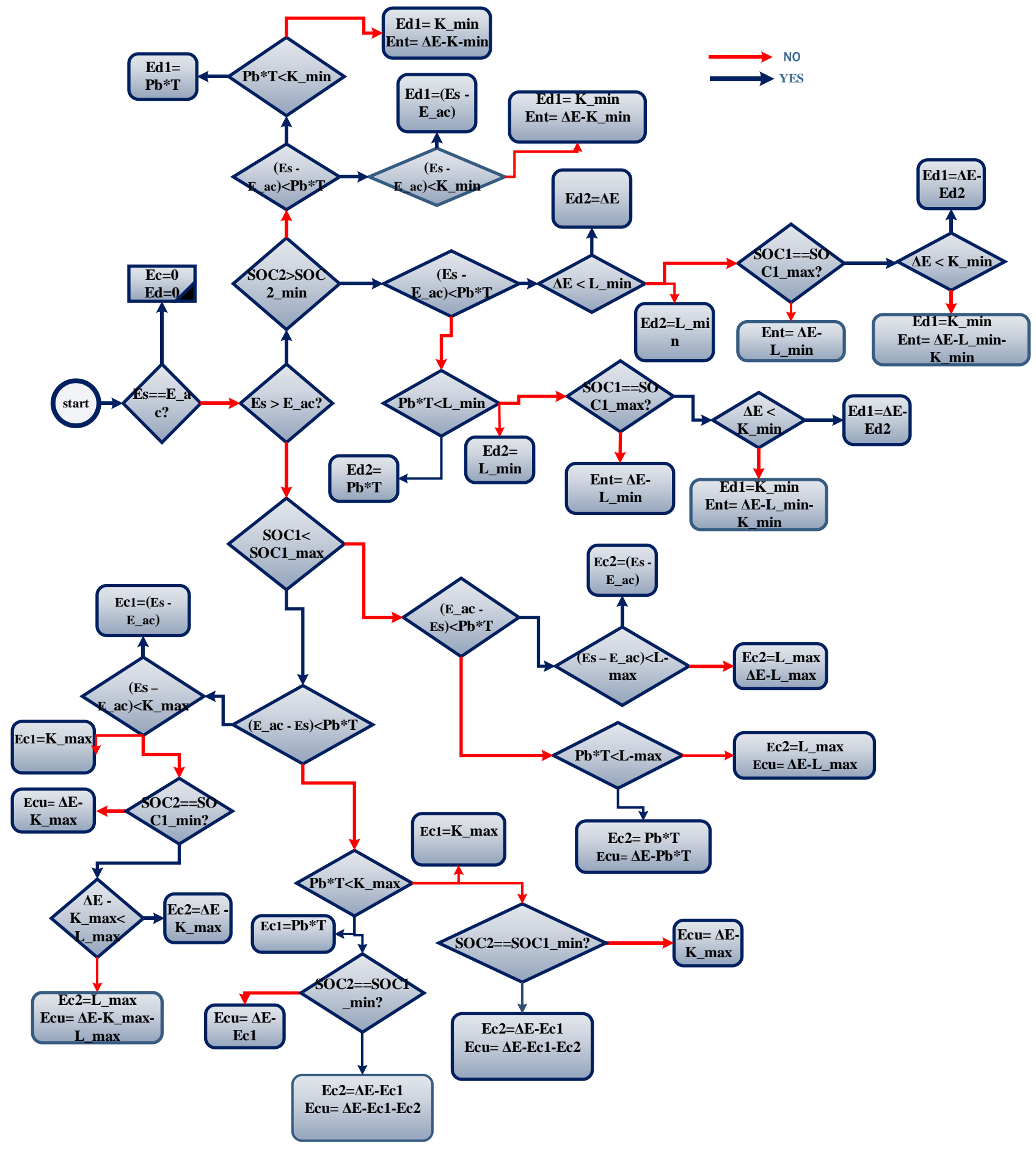

Figure 7. Control algorithm of asynchronous state exchanging strategy.

\subsubsection{Techno-Economic Analysis}

The embedded BESS can massively boost the value of index probabilities of meeting generating schedule (PMGS) of the BESS-integrated WFs while decreasing the corresponding expected injected energy deviations (EIED) [36,39]. 
For a certain duration, the PMGS and EIED can be computed as follows:

$$
\begin{gathered}
M_{P M G S}=P_{r}\left\{P_{W+B E S S, i}=P_{S, i}\right\} i=1,2, \ldots, n \\
M_{E I E D}=\frac{1}{n} \sum_{i=1}^{n}\left(P_{s, i}-P_{W+B E S S, i}\right)
\end{gathered}
$$

where, $P_{r}$ is defined as the probability of the selected event.

Further, the operation benefits of the WF, integrated with BESS (OBB), are comprised of two aspects and can be defined as follows:

$$
M_{O B B}=\sum_{i=1}^{n} M_{i n, i}-\sum_{i=1}^{n} M_{i n-w i n d, i}
$$

where, $M_{i n-w i n d, i}$ is the revenue of the WF at DI $i$ and $M_{i n, i}$ is the revenue of the BESSintegrated WF.

Further, operation costs of the BESS (OCB) are defined as

$$
M_{O C B}=\frac{B_{1}+B_{2}}{2 B_{\text {total }}} M_{\text {invest }} * E_{c}
$$

where, $B_{1}, B_{2}$ are the numbers of charge/discharge cycles BESS I/II, $B_{\text {total }}$ is the number of charge-discharge cycles the BESS and $M_{\text {invest }}$ is the cost of the BESS with unit capacity.

At last, operational profits of the BESS $M_{O P B}$ is given as:

$$
M_{O P B}=M_{O B B}-M_{O C B}
$$

The energy curtailed units (ECUs) can also be defined as follows:

$$
E C U=\sum_{i=1}^{n}\left(P_{w, i}-P_{s, i}-P_{c h, i}\right) T
$$

where, $P_{c h, i}$ represents the charged power.

\subsubsection{Optimization Process of the BESS Operation}

The charging and discharging energy of the BESS are proportional to its SOC in the previous DI, implying that the BESS procedure is of a sequential nature. In this paper, linear programming optimization is used to simulate BESS operations in order to calculate the economic indices PMGS, EIED, ECU, OBB, OCB, and OPB. The detailed simulation stages are summed up below [36,39].

Stage 1: Set the BESS's initial charging and discharging states and SOC values.

Stage 2: Compute the probability distribution's shape parameters based on short-term forecast values of the current DI.

Stage 3: At DI, i generate probability-distributed wind power at random by using the following equation:

$$
P_{w, i}=G_{w i n d} F^{-1}(c)=G_{w i n d}\left[\gamma-\frac{1}{\alpha} \ln \left(c^{-\frac{1}{\beta}}-1\right)\right]
$$

where, $G_{\text {wind }}$ represents the WF's installed capacity, $c$ uniformly distributed random number $[0,1]$ and $F^{-1}($.$) is inverse function of cumulative distribution function (CDF).$

Stage 4: Assess the BESS charging/discharging energy as well as the wind energy curtailed for power generation in order to meet the expected production timeframes. 
Stage 5: Determine the SOC of the BESS at the current DI using the following equations.

$$
\begin{gathered}
S_{I, i}=\left\{\begin{array}{c}
S_{I, i-1}-\left(\eta_{c h} P_{b I, i}\right) /\left(0.5 E_{c}\right) P_{b I, i}<0 \\
S_{I, i-1} P_{b I, i}=0 \\
S_{I, i-1}-\left(P_{b I, i} T\right) /\left(0.5 \eta_{d i s} E_{c}\right) P_{b I, i}>0
\end{array}\right. \\
S_{I I, i}=\left\{\begin{array}{c}
S_{I I, i-1}-\left(\eta_{c h} P_{b I I, i}\right) /\left(0.5 E_{c}\right) P_{b I I, i}<0 \\
S_{I I, i-1} P_{b I I, i}=0 \\
S_{I I, i-1}-\left(P_{b I I, i} T\right) /\left(0.5 \eta_{d i s} E_{c}\right) P_{b I I, i}>0
\end{array}\right.
\end{gathered}
$$

Stage 6: If some portion of the BESS achieves its maximum charging/discharging status, it must be replaced immediately.

Stage 7: Let $i=i+1$ and steps 1-6 should be repeated till the intended research time range is completely covered. Following that, the indices PMGS, EIED, ECU, OBB, OCB, and $\mathrm{OPB}$ with regard to the current trial may be obtained.

Stage 8: Procedures 1-7 should be repeated until the coefficient of variation is less than the tolerance error.

\subsubsection{Battery Selection}

Lithium-ion batteries (Li-ion) are used in this work due to their compatibility as compared to other types of BESS technologies when it is integrated into the wind power farm. High efficiency (85-95\%), high energy capacity, better response times and a long life span at 100\% depth of discharge (DOD) up to 10,000 cycles are some of its remarkable features [7].

Unlike battery type selection, the size of the battery was determined based on a series of simulations. So, in order to determine the size of the battery, the performance of the wind farm was tested with various battery capacities in all cases of operating strategies (single, simultaneous, and asynchronous). In all cases, technical indices (PMGS, EIED, and ECU) appeared to improve with an increase in battery capacity. Contrarily, the profit of a battery integrated wind farm showed an increment with an increase in battery capacity for small battery sizes in the simultaneous state exchanging strategy, and it showed a negative increment for other cases as described in the result section. So, the BESS capacity with maximum profit was chosen.

\subsubsection{Economic Structure}

The country's entire power grid is owned and operated by two large categories of Ethiopian electricity corporations: Ethiopian Electric Power (EEP) and Ethiopian Electric Utility (EEU) [6]. As both are state-owned, one is responsible for generation and transmission, while the other is responsible for distribution, i.e., the sale of the power produced. So, the energy generated by the wind farm is assumed to be sold by EEU. It is assumed that the power generated by each generating unit is distributed among the demand sectors according to its percentage of demand composition. An internal demand composition of EEU's distribution system as per the 2017 report and the average electricity price according to a newly enhanced tariff is shown in Table 1 [41].

Table 1. An internal demand composition and average price.

\begin{tabular}{ccc}
\hline Demand Sector & Composition (\%) & Average Price ETB/kWh \\
\hline Domestic & 38 & 1.880 \\
\hline Commercial & 24 & 2.1240 \\
\hline Industrial & 36 & 1.531 \\
\hline Street & 2 & 2.1240 \\
\hline
\end{tabular}


So, it is assumed that the power generated by the wind farm is distributed to each demand sector according to its percentage, and the income for EEU due to the wind farm's energy is assumed to be the income of the wind farm.

Based on Table 1, the economic attributes of EEU due to the BESS-integrated wind farm, i.e., $\mathrm{OBB}, \mathrm{OCB}$, and $\mathrm{OPB}$, can be calculated using the following equations.

$$
\mathrm{OBB}=P_{w-B E S S} \times(0.38 \times 1.88+0.24 \times 2.124+0.36 \times 1.531+0.02 \times 2.124)
$$

\section{Results and Discussion}

\subsection{Technical Performances of WF Integrated with Different BESS Capacities}

The battery energy storage system (BESS) is developed along with the wind farm. With the increase in BESS capacity, the technical performance of the BESS integrated WF to meet the generation schedule improves. This improvement is irrespective of the state exchange strategy and number of batteries, as shown in Figures 8-10. The values of the indexes EIED and ECU decrease as BESS capacity increases. On the other hand, the PMGS index value increases monotonically as the capacity of the battery energy storage system increases.

Figures 8-10 show the impact of the state exchange strategy on deciding the $\mathrm{WF}^{\prime} \mathrm{s}$ technical efficiency. In an asynchronous strategy, during certain DIs, both sections of the BESS can be in the same charging and discharging condition. If both portions are in good charging condition, the deficiencies will not be compensated. As a consequence, WF cannot monitor the preferred power schedules. In comparison, if both sections are in discharging condition, the discharge power accessible will be subsequently improved, and technical efficiency will be enhanced when reaching the required generation schedules, but there is no room for surplus energy that will increase the ECU index.

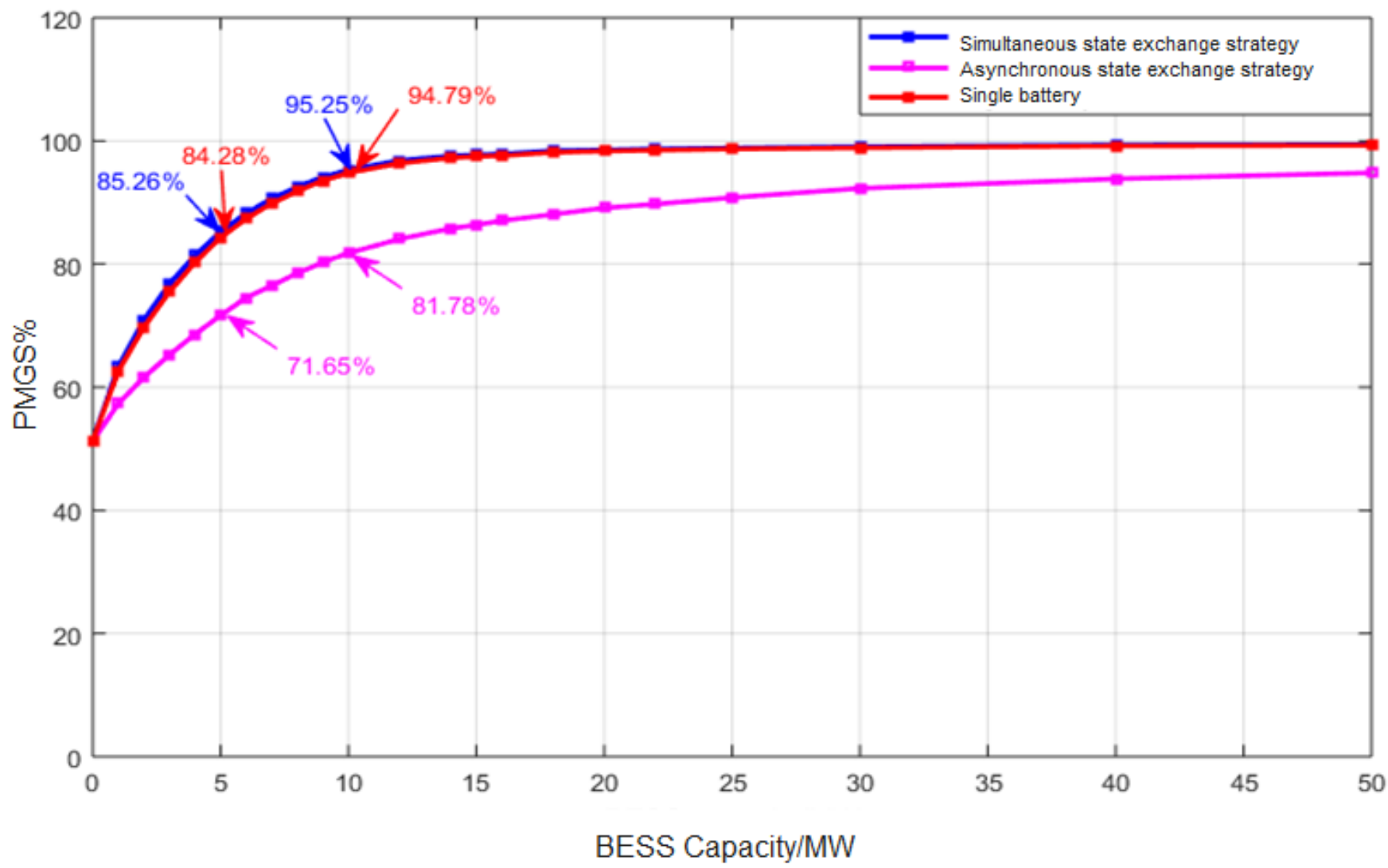

Figure 8. Probabilities of meeting generation schedule with various BESS capacities. 


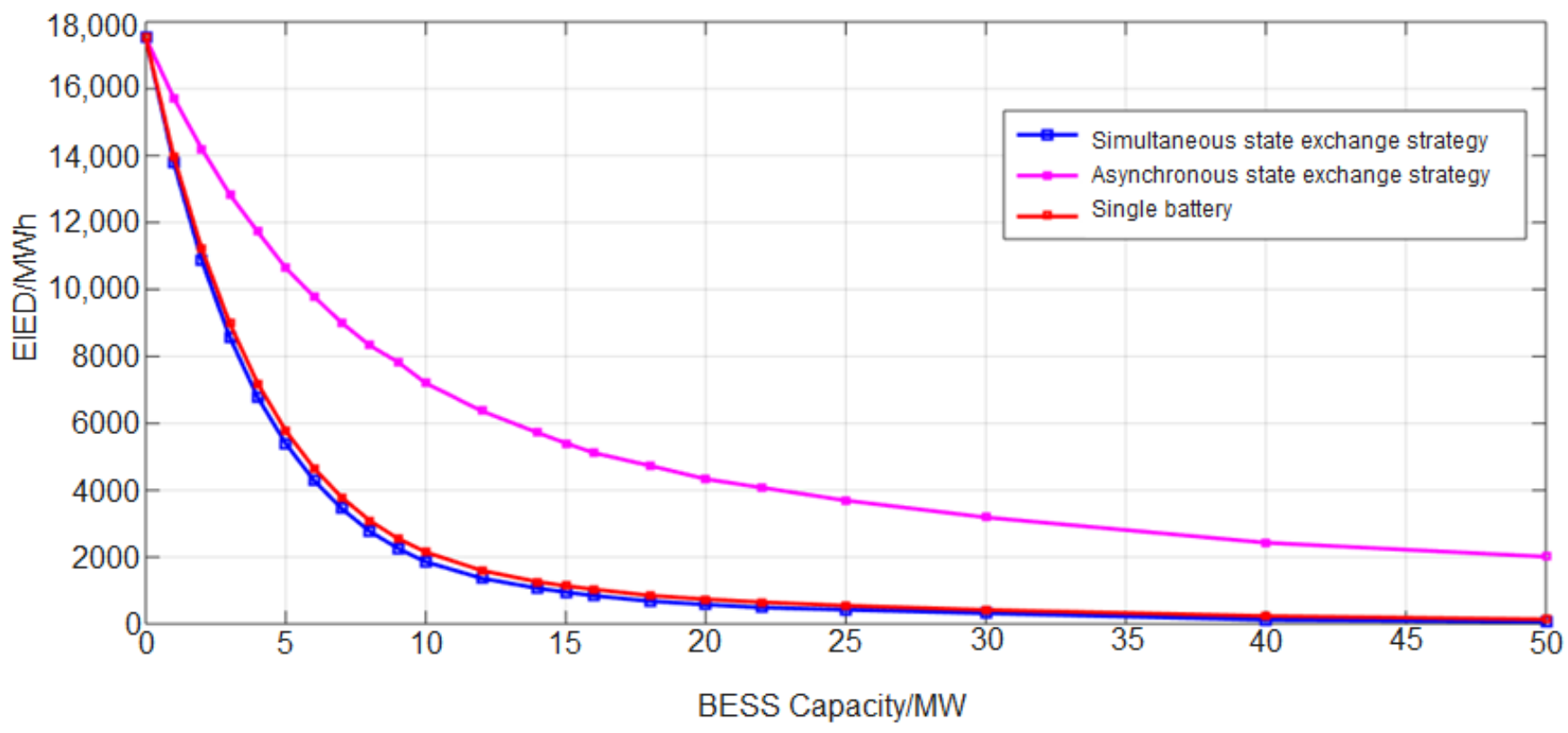

Figure 9. Expected injected energy deviation in various BESS capacities.

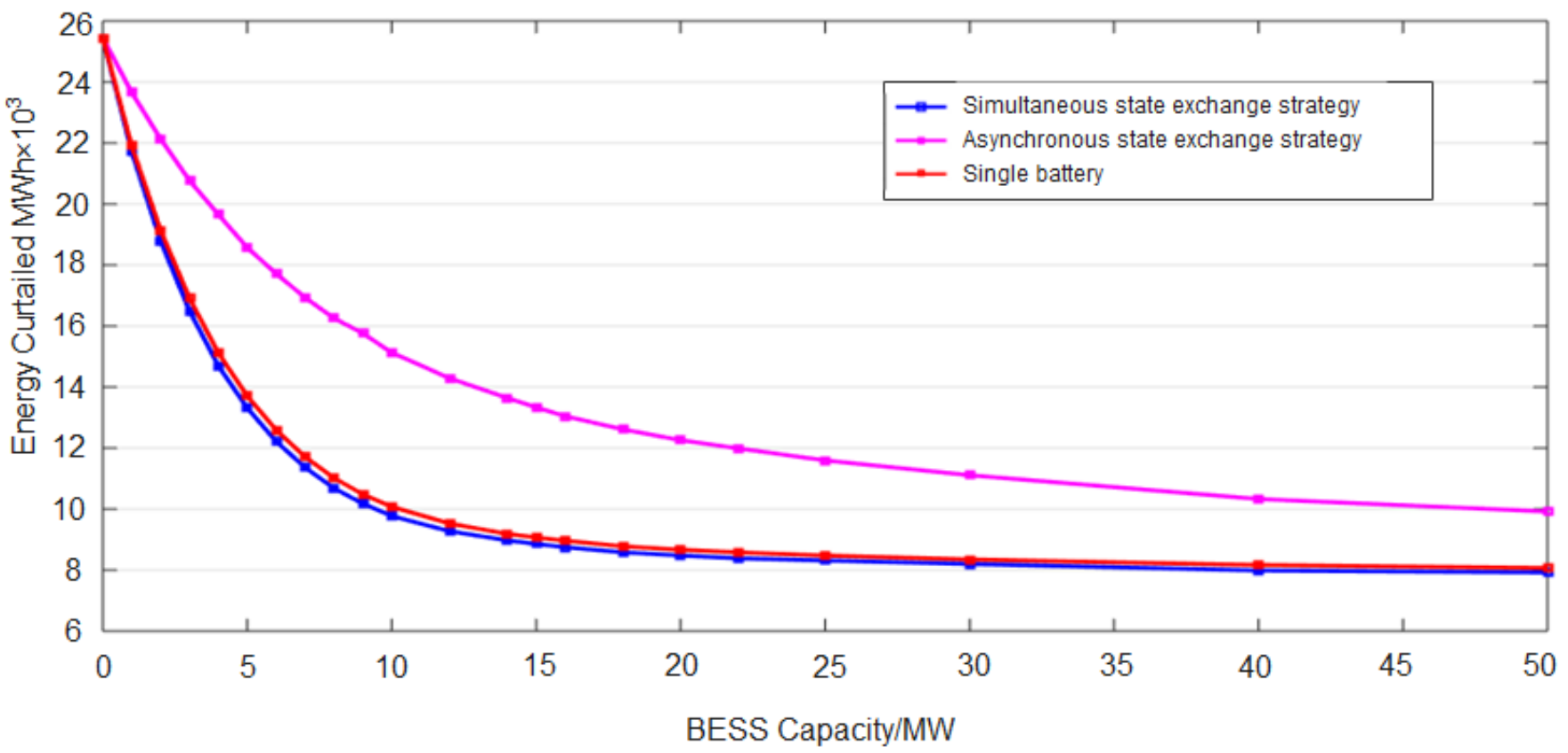

Figure 10. Energy curtailed with various BESS capacities.

These two opposite factors affect the technical efficiency of BESS in achieving the required generation schedules. Therefore, the simultaneous strategy will provide better technical output on most BESS capacity values in order to meet the necessary scheduled production, as shown in Figures 8-10. In other words, the simultaneous strategy will provide the greater PMGS index and the lesser EIED and ECU index for most BESS capability values.

In fact, at the same dispatch interval, both batteries are in the same state, which does not always reduce WF's technical efficiency. If, at the same dispatch interval, both sections of the battery energy storage system are in discharge states where more energy is required from the BESS, the available discharge power of these DIs is subsequently increased. The power deficit that cannot be met by one battery will therefore be balanced by both, which implies that the technological efficiency of these DIs tends to be increased. From Figures 8-10, it is clear that after $12 \mathrm{MW}$ the value of performance indices are more or 
less constant for further capacity addition of the battery energy storage system. Therefore, $12 \mathrm{MW}$ is selected.

\subsection{Economic Analysis}

The cost of batteries is currently very high, so the economic feasibility is very important. In different state exchange strategies, the values of the OBB, OCB, and OPB indices are illustrated in Tables $2-4$, respectively. Table 5 shows that the benefits derived from the equation-based BESS increase with the rise in battery capacity irrespective of which state exchange strategy is used. It can be shown that if a simultaneous state exchange strategy is implemented, the wind farm's OBB is stronger than the asynchronous state exchange strategy or single battery activity.

However, the cost of operation of the BESS increased significantly with increasing size when a single battery operation was adopted rather than a two-battery operation (simultaneous or asynchronous state exchanging strategy). The main reason for this cost difference between those operating strategies is the total number of batteries used per year.

Table 2. Operation benefit of BESS integrated wind farm (in Ethiopian birr (ETB)) with various BESS capacities in different operating strategies.

\begin{tabular}{cccc}
\hline Size (MW) & Simultaneous Operation & Asynchronous Operation & Single Battery \\
\hline 1 & $7,989,898$ & $5,005,956$ & $7,675,799.2$ \\
\hline 2 & $13,997,046$ & $9,030,352$ & $13,525,897$ \\
\hline 3 & $18,728,165$ & $12,485,443$ & $18,178,491$ \\
\hline 4 & $22,438,462$ & $15,174,918$ & $21,888,788$ \\
\hline 5 & $25,304,617$ & $17,903,654$ & $24,774,574$ \\
\hline 6 & $27,464,049$ & $19,964,930$ & $26,992,900$ \\
\hline 7 & $29,132,701$ & $21,535,426$ & $28,700,814$ \\
\hline 8 & $30,389,098$ & $23,047,029$ & $30,035,736$ \\
\hline 9 & $31,351,026$ & $24,008,958$ & $31,017,296$ \\
\hline 10 & $32,077,381$ & $25,245,723$ & $31,743,650$ \\
\hline 12 & $32,960,785$ & $26,659,170$ & $32,646,686$ \\
\hline
\end{tabular}

Table 3. The number of charge/discharge cycles for each battery under different operating strategy.

\begin{tabular}{cccccc}
\hline \multirow{2}{*}{$\begin{array}{c}\text { Size } \\
(\mathbf{M W})\end{array}$} & \multicolumn{2}{c}{ Simultaneous Operation } & \multicolumn{2}{c}{ Asynchronous Operation } & Single Battery \\
\cline { 2 - 6 } & No. Cycles (B1) & No. Cycles (B2) & No. Cycles (B1) & No. Cycles (B2) & No. Cycles \\
\hline 1 & 10,656 & 10,182 & 11,380 & 4945 & 28,860 \\
\hline 2 & 11,076 & 10,254 & 11,529 & 4931 & 28,904 \\
\hline 3 & 10,909 & 10,283 & 11,380 & 5052 & 28,917 \\
\hline 4 & 10,637 & 10,298 & 11,331 & 5095 & 28,969 \\
\hline 5 & 10,223 & 10,379 & 10,967 & 5491 & 28,988 \\
\hline 6 & 9773 & 10,505 & 10,915 & 5525 & 29,007 \\
\hline 7 & 9739 & 10,266 & 10,525 & 5900 & 29,030 \\
\hline 8 & 9493 & 10,313 & 10,267 & 6165 & 29,050 \\
\hline 9 & 9228 & 10,434 & 10,221 & 6223 & 29,075 \\
\hline 10 & 9106 & 10,464 & 10,008 & 6394 & 29,066 \\
\hline 12 & 8997 & 10,423 & 9677 & 6703 & 29,088 \\
\hline
\end{tabular}


Table 4. Operation profit of BESS integrated WF (OPB) with various battery capacities in (ETB).

\begin{tabular}{cccc}
\hline Size MW & Simultaneous Operation & Asynchronous Operation & Single Battery \\
\hline 1 & $2,289,898$ & $-694,044$ & $-874,201$ \\
\hline 2 & $2,597,046$ & $-2,369,648$ & $-3,574,103$ \\
\hline 3 & $1,628,165$ & $-4,614,557$ & $-7,471,509$ \\
\hline 4 & $-361,538$ & $-7,625,082$ & $-1.2 \times 10^{7}$ \\
\hline 5 & $-3,195,383$ & $-1.1 \times 10^{7}$ & $-1.8 \times 10^{7}$ \\
\hline 6 & $-6,735,951$ & $-1.4 \times 10^{7}$ & $-2.4 \times 10^{7}$ \\
\hline 7 & $-1.1 \times 10^{7}$ & $-1.8 \times 10^{7}$ & $-3.1 \times 10^{7}$ \\
\hline 8 & $-1.5 \times 10^{7}$ & $-2.3 \times 10^{7}$ & $-3.8 \times 10^{7}$ \\
\hline 9 & $-2 \times 10^{7}$ & $-2.7 \times 10^{7}$ & $-4.6 \times 10^{7}$ \\
\hline 10 & $-2.5 \times 10^{7}$ & $-3.2 \times 10^{7}$ & $-5.4 \times 10^{7}$ \\
\hline 12 & $-3.5 \times 10^{7}$ & $-4.2 \times 10^{7}$ & $-7 \times 10^{7}$ \\
\hline
\end{tabular}

Table 5. Operation profits (OPB) and probabilities of meeting the generation schedule.

\begin{tabular}{ccc}
\hline Size (MW) & Profit (ETB) & PMGS (\%) \\
\hline 1 & $2,289,898$ & 63.33 \\
\hline 2 & $2,597,046$ & 70.88 \\
\hline 3 & $1,628,165$ & 76.81 \\
\hline 4 & $-361,538$ & 81.39 \\
\hline 5 & $-3,195,383$ & 85.26 \\
\hline 6 & $-6,735,951$ & 88.24 \\
\hline 7 & $-1.1 \times 10^{7}$ & 90.64 \\
\hline 8 & $-1.5 \times 10^{7}$ & 92.54 \\
\hline 10 & $-2 \times 10^{7}$ & 94.12 \\
\hline 12 & $-2.5 \times 10^{7}$ & 95.29 \\
\hline
\end{tabular}

As explained in the literature, for the selected time frame, the number of charging and discharging cycles the BESSs have undergone has a direct effect on the BESS's operating costs as it defines the number of batteries used. Based on the fact that the approximate life cycle of lithium-ion batteries is charge/discharge cycles, three batteries' lives were totally consumed within the studied time horizon if a single battery operation was adopted, whereas two batteries were sufficient if an asynchronous or simultaneous state exchanging strategy was adopted. So, integrating a single battery into the wind farm was found to be costlier than integrating two batteries, regardless of its state exchanging strategy. It can be seen from Table 4 that the BESS charge-discharge periods were smaller when the asynchronous state exchange strategy was implemented. Therefore, for the study period, two batteries were more than enough. The explanation for this limited number of cycles is that, unlike the simultaneous state exchange strategy and single battery service, the asynchronous strategy will guarantee that the BESS's total charge-discharge cycles are changed from charging to discharging condition if only it is fully charged, and if it is completed, it will change from discharging to charging condition. Table 3 presents the number of charge and discharge cycles for each battery under different operating strategies.

Table 3 shows the dramatic impact of the state exchange strategy on the economic characteristics of WF. Battery energy storage system operating profit is practically benefits minus costs, so large variations in costs can lead to substantial discrepancies between 
the OPB index values between operating strategies, as seen in Table 4. Specifically, the OPB index in the simultaneous state exchange strategy for battery capacity of 1,2 , and $3 \mathrm{MW}$ is remarkably better than others that are larger than zero. However, the OPB of the BESS-integrated wind farm is negative in both single battery operation and two-battery operation under the asynchronous state exchanging strategy.

So, from Table 4, it can be seen that the wind farm will experience an economic loss if the asynchronous operation strategy of two batteries is adopted or a single battery is integrated. Table 4 also shows that the OPB index shows an increasing trend for simultaneous state exchange strategies when the BESS capacity increases from 1 to $2 \mathrm{MW}$ and then shows a decrease from 2 to $3 \mathrm{MW}$. That is, when $2 \mathrm{MW}$ of BESS capacity is available and the maximum value is $2,597,046 \mathrm{ETB}$, the OPB index reaches its maximum value and the probability of meeting the generation schedule is 70.88 percent, whereas when capacity exceeds $3 \mathrm{MW}$, the BESS integrated OPB is negative.

Table 5 illustrates the profit and the corresponding probabilities of meeting the desired generation schedule with different battery capacities when a simultaneous state exchanging strategy is adopted.

Figures 11-13 show the probabilities of the WF for meeting the scheduled generation, the total amount of energy saved from being curtailed, and the total amount of energy not delivered at different sizes of BESS over the year after 35,040 dispatch intervals, which represent time duration for which WF supplies the demands. To show the effectiveness of BESS clearly, the power curve of delivered power under different circumstances (single battery, simultaneous, and asynchronous) is presented in Figures 12 and 13. The performance of the wind farm under each operating condition is summarized in Tables 6 and 7 . Since it is difficult to draw the power curve of the whole year, a typical 48-h simulation was chosen and simulated with a battery size of 2 and 3 MW. On both battery sizes, the power curve of simultaneous operation was found to be closer to the schedule than the others.

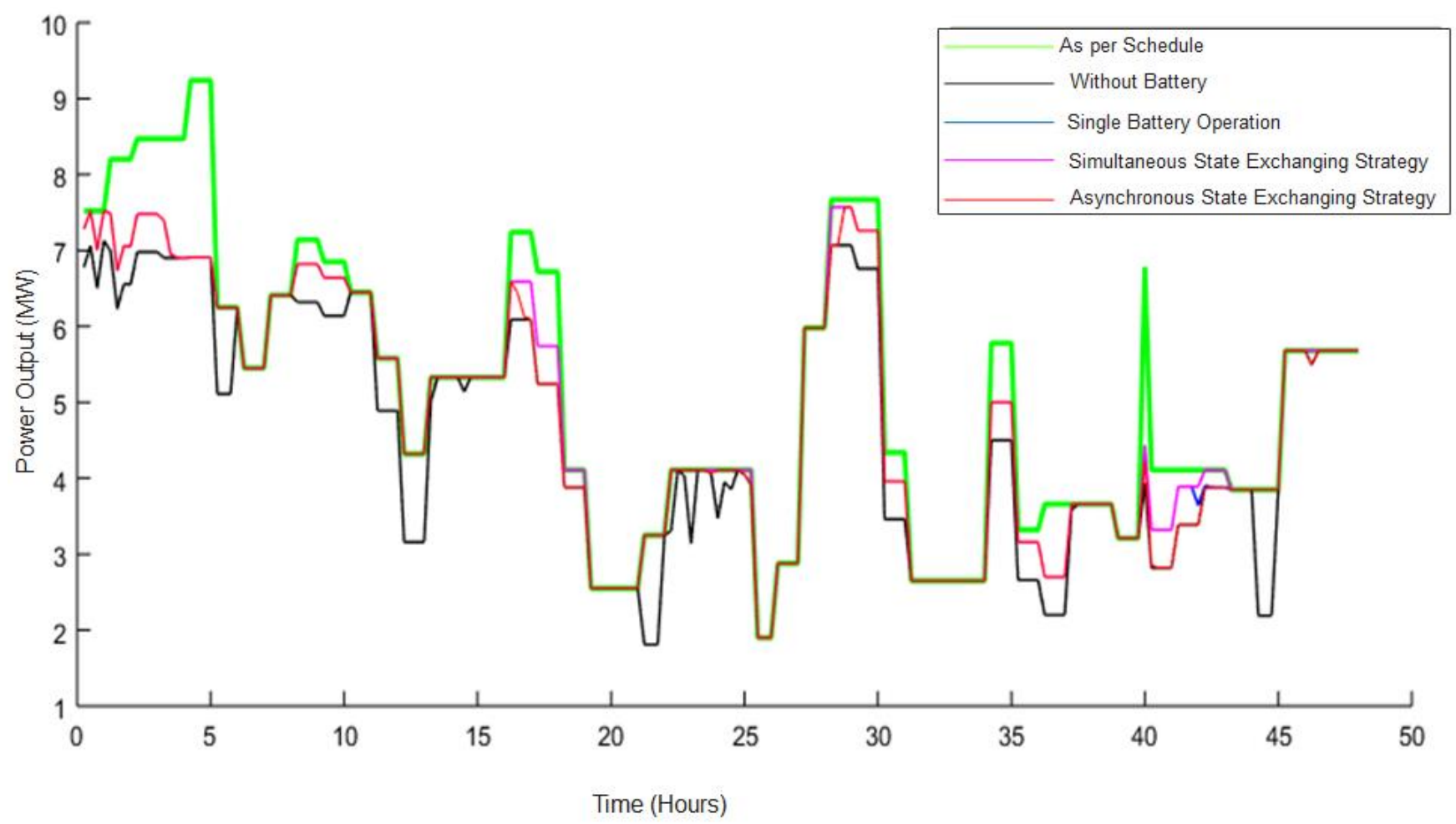

Figure 11. Power curve of output of BESS-integrated wind farm when $2 \mathrm{MW}$ of battery. 


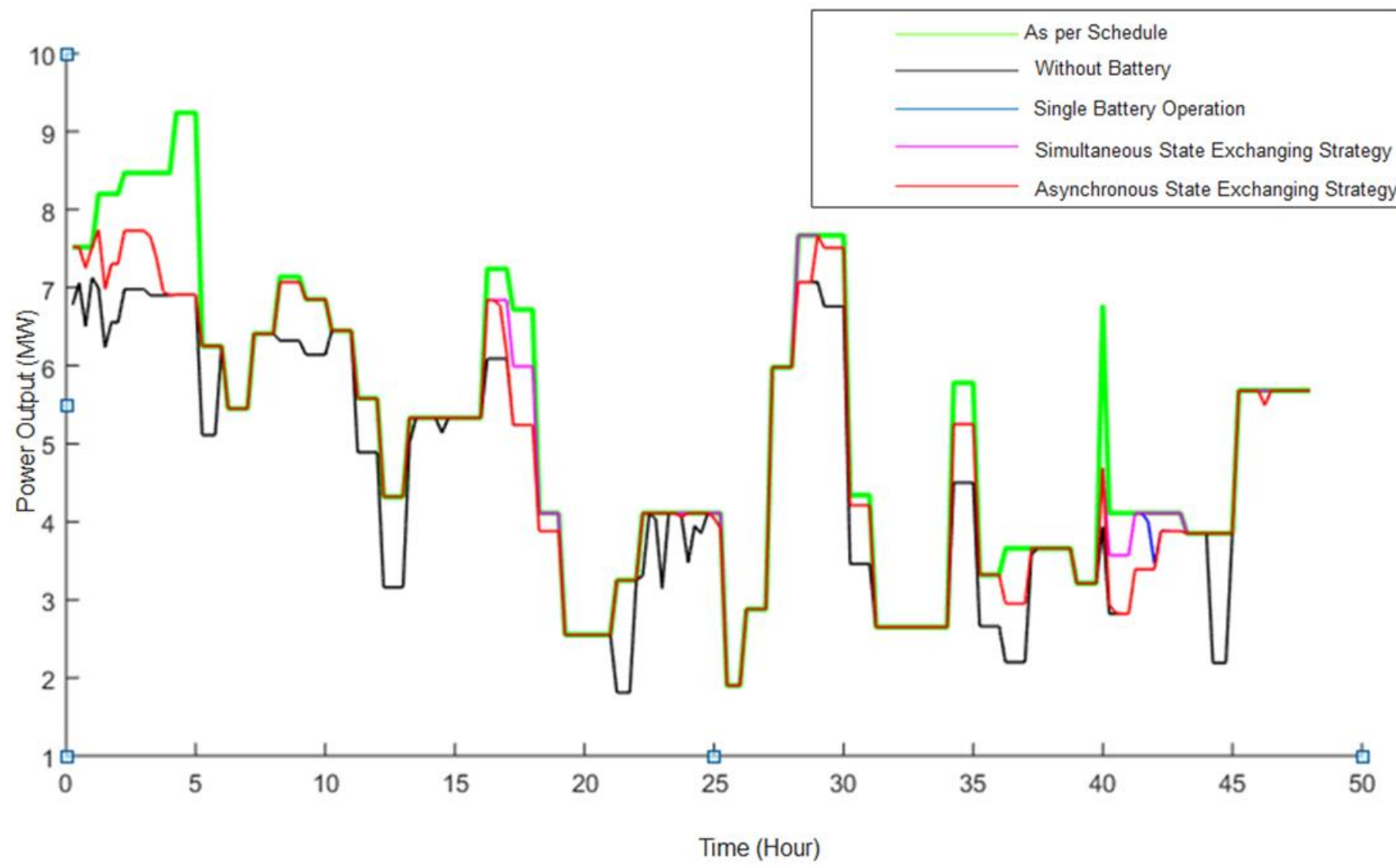

Figure 12. Power curve of output of BESS-integrated wind farm when $3 \mathrm{MW}$ of battery.

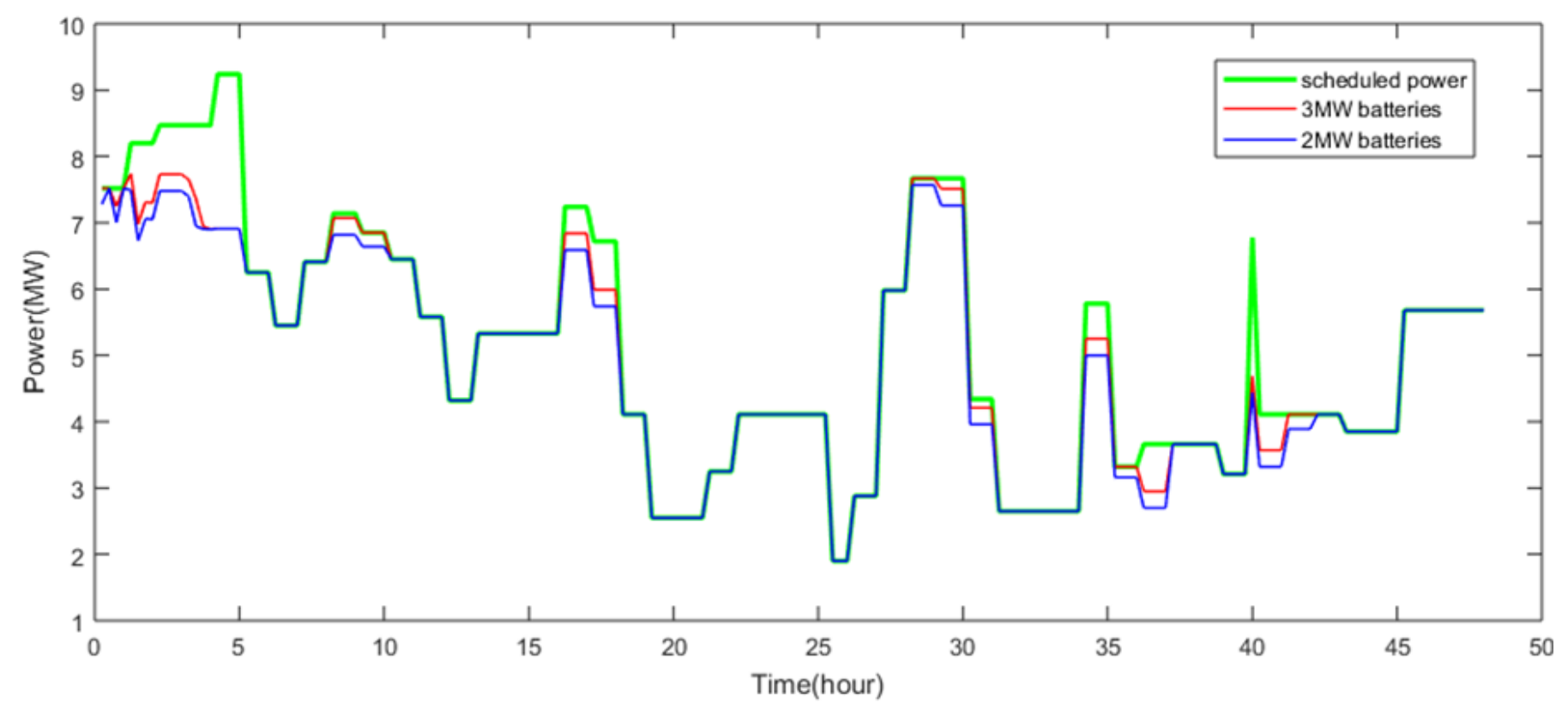

Figure 13. Power curve of output of BESS-integrated wind farm under 2 and $3 \mathrm{MW}$ of battery in simultaneous state exchanging strategy. 
Table 6. Performance indices of BESS-integrated wind farm with 2 MW battery.

\begin{tabular}{cccc}
\hline Operation Strategy & PMGS (\%) & EIED (MW) & ECU (MW) \\
\hline No battery & 44.27 & 107.28 & 73.62 \\
\hline Single battery & 63.02 & 54.23 & 63.66 \\
\hline Synchronous & 58.85 & 61.05 & 73.15 \\
\hline Simultaneous & 65.1 & 50.42 & 56.12 \\
\hline
\end{tabular}

Table 7. The performance indices of BESS-integrated wind farm with $3 \mathrm{MW}$ of battery.

\begin{tabular}{cccc}
\hline Operation Strategy & PMGS (\%) & EIED (MW) & ECU (MW) \\
\hline No battery & 44.27 & 107.28 & 73.62 \\
\hline Single battery & 70.83 & 79.69 & 49.99 \\
\hline Asynchronous & 64.06 & 49.85 & 61.95 \\
\hline Simultaneous & 73.96 & 36.21 & 38.71 \\
\hline
\end{tabular}

As shown in the Table 6, the probability of the WF meeting the generation schedule is $44.27 \%$. This is achieved by curtailing the surplus power when the actual wind power exceeds the predetermined schedule. However, in the presence of BESS, the curtailment option is taken only when the batteries are fully charged or when the surplus energy is beyond the charging rate of the BESS.

From the simulation of $48 \mathrm{~h}$ (192 dispatch intervals), in a simultaneous state exchanging strategy, the probability of meeting the generation schedule with 2 and $3 \mathrm{MW}$ of battery is 65.1 and $73.96 \%$, respectively. On other days, the PMGS of the wind farm with both battery sizes may be more than 80,90 , or even lower than $60 \%$. This shows that the accuracy of the forecast also affects the performance of the BESS integrated wind farm. Inaccurate forecasts will reduce the probability of the wind farm meeting the desired generation schedule, whereas accurate forecasts will maximize the PMGS. The greater the number of dispatch intervals considered, the better or more accurate the result will be in terms of the performance of the BESS integrated wind farm. Taking this into consideration, 35,040 dispatch intervals were considered in the simulation and PMGS of 70.88 and $76.81 \%$ was obtained for 2 and 3 MW batteries, respectively.

Here, a single battery operation and an asynchronous state exchanging strategy are not discussed because of their negative economic performance. As discussed in the above sections, even though the maximum profit was achieved with a 2 MW battery, the performance is much better when a $3 \mathrm{MW}$ battery is used, and its profit is not the worst. Table 8 shows the input parameters of the two 2 MW batteries and the two 3 MW batteries. Figure 13 shows the power injected by the BESS integrated wind farm during those $48 \mathrm{~h}$ with 3 and 2 MW batteries. It is clear that the BESS-integrated wind farm output catches the schedule better with 3 than with $2 \mathrm{MW}$.

Table 8. Input parameters of two $2 \mathrm{MW}$ batteries and the two $3 \mathrm{MW}$ batteries.

\begin{tabular}{ccc}
\hline Parameters & Values of $\mathbf{2}$ MW Batteries & Values of $\mathbf{3}$ MW Batteries \\
\hline$\eta$ & 0.9 & 0.9 \\
\hline$S O C_{\min }$ & $10 \%$ & $10 \%$ \\
\hline$S O C_{\max }$ & $90 \%$ & $90 \%$ \\
\hline$P_{\max }$ & $2 \mathrm{MW}$ & $3 \mathrm{MW}$ \\
\hline$c_{-}$rate & 0.25 & 0.25 \\
\hline price $(\$)$ & $130 / \mathrm{kWh}$ & $130 / \mathrm{kWh}$ \\
\hline Life cycle & 10,000 cycles & 10,000 cycles \\
\hline
\end{tabular}




\subsection{Achievements}

This work proposed the battery energy storage system technology for a practical wind farm. For that purpose, the integration of two independently controlled BESS into the WF is performed to balance stochastic power deviations between actual wind power and scheduled power. This will provide the most adequate performance indices (PMGS, EIED, and ECU) for the selected wind farm system. The simultaneous operation of the battery energy storage system provides better results as compared to the other operation cases of the selected system, i.e., without the BESS, a single battery energy storage system, and asynchronous operation of the BESS. Further, these performance indexes are computed under two different battery capacity structures, such as 2 and 3 MW battery systems. This analysis provided information about the capacity of the battery energy storage system that will be most suitable for the selected WF. This research work provided a reference document for the Ethiopian electric power system to improve the system's performance by incorporating the battery energy storage system into a synchronous mode of operation.

\section{Conclusions}

A methodology to incorporate BESS into WFs has been developed to allow the WFs associated with battery energy storage systems to meet, to some degree, the required generation schedules. A number of indices, such as PMGS, EIED, ECU, OCB, OPB, and $\mathrm{OBB}$, are determined to assess the technical and cost-effective performance of the required generation schedules. A case study on a real WF, i.e., ADAMA-I wind farm, Ethiopia, was performed to check the feasibility of the proposed technique. The theoretical support for the design of a BESS-integrated WF can be provided by the research in this paper. In this work, a dual battery operation with two different BESS state-exchanging strategies is used, known as the "simultaneous state exchanging strategy" and the "asynchronous state exchanging strategy". In this dual battery operation, the impacts of state exchanging strategy on the performance of BESS-integrated WFs are studied. It was found that the economic and technical performance of a wind farm was better when a simultaneous stateexchanging strategy was implemented. This shows the adopted state exchanging strategy, as well as the number of batteries integrated into the wind farm, have a direct impact on technical performance (PMGS, EIED, and ECU) and economic aspects (OBB, OCB, and $\mathrm{OPB}$ ) of the wind farm. The case study proves that the operation benefits attributed to the BESS can completely cover the operation costs of the BESS in the assumed power market mechanism only when a simultaneous state exchanging strategy is adopted. Future work will include the effect of wind power fluctuation on grid voltage, frequency, and reactive power. Furthermore, the effect of a greater depth of discharge on battery life loss may also be incorporated. Additionally, different combinations of the ESS systems can be utilized to enhance the stability of the system.

Author Contributions: Conceptualization, A.S. and B.K.; methodology, A.S.; software, B.K.; validation, A.S., B.K. and I.G.; formal analysis, B.K.; investigation, B.K.; resources, B.K.; data curation, A.S.; writing—original draft preparation, B.K.; writing—review and editing, O.P.M.; visualization, B.K.; supervision, B.K.; project administration, B.K.; funding acquisition; A.E.-S. and A.Y.A. reviewed the paper. All authors have read and agreed to the published version of the manuscript.

Funding: There is no funding for this research.

Institutional Review Board Statement: Not applicable.

Informed Consent Statement: Not applicable.

Data Availability Statement: Data will be available on requrest.

Conflicts of Interest: There is no conflict of interest. 


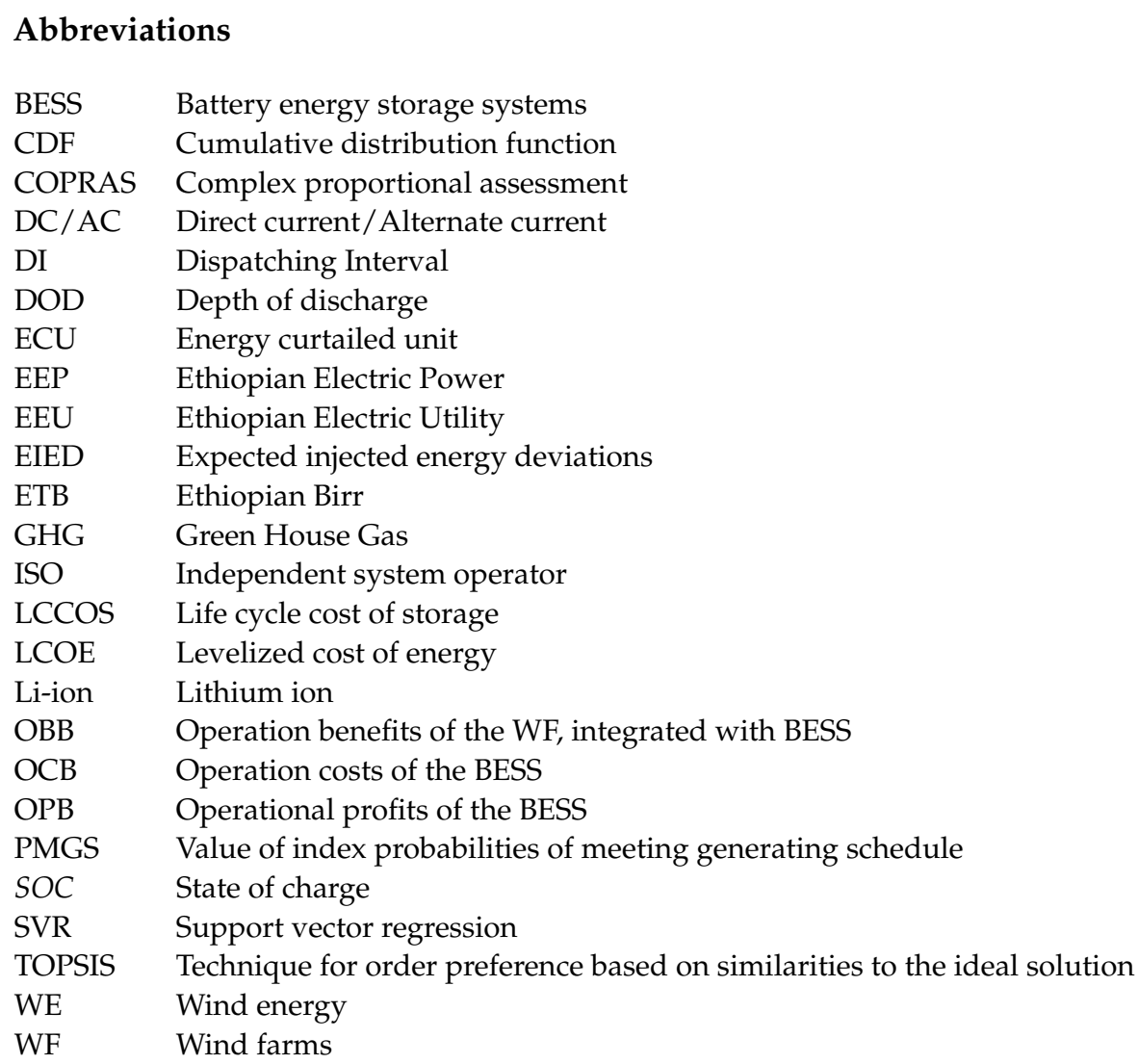

\section{References}

1. International Energy Agency. World Energy Outlook 2011. Available online: https://www.iea.org/reports/world-energy-outlook2011 (accessed on 16 September 2021).

2. Ye, X.; Qiao, Y.; Lu, Z.; Min, Y.; Wang, N. Study on multi-scale unit commitment optimization in the wind-coal intensive power system. J. Electr. Eng. Technol. 2013, 8, 1590-1604. [CrossRef]

3. Ethiopian Electric Power. The Ethiopian Energy Sector-Investment Opportunities. Available online: https://www.developingmarkets. $\mathrm{com} /$ sites/default/files/AA\%20Eth\%20Energy\%20Sector\%20Presentation\%20London.pdf (accessed on 16 September 2021).

4. Troy, N.; Denny, E.; O'Malley, M. Base-load cycling on a system with significant wind penetration. IEEE Trans. Power Syst. 2010, 25, 1088-1097. [CrossRef]

5. Heier, S.; Waddington, R. Grid Integration of Wind Energy Conversion Systems, 2nd ed.; John Wiley and Sons: Hoboken, NJ, USA, 2006

6. Wind Energy the Facts. Understanding Variable Output Characteristics of Wind Power. Available online: https://www.windenergy-the-fact.org/understanding-variable-output.html (accessed on 14 September 2021).

7. Kurzweil, P. Lithium Battery Energy Storage: State of the Art Including Lithium-Air and Lithium-Sulfur Systems. In Electrochemical Energy Storage for Renewable Sources and Grid Balancing; Elsevier: Amsterdam, The Netherlands, 2015; pp. $269-307$.

8. Oudalov, A.; Chartouni, D.; Ohler, C. Optimizing a Battery Energy Storage System for Primary Frequency Control. IEEE Trans. Power Syst. 2007, 22, 1259-1266. [CrossRef]

9. Schweer, D.; Maaz, A.; Moser, A. Optimization of frequency containment reserve provision in M5BAT hybrid battery storage. In Proceedings of the 2016 13th International Conference on the European Energy Market (EEM), Porto, Portugal, 6-9 June 2016.

10. Korpaas, M.; Holen, A.T.; Hildrum, R. Operation and sizing of energy storage for wind power plants in a market system. Int. J. Electr. Power Energy Syst. 2003, 25, 599-606. [CrossRef]

11. Fitzgerald, G.; Mandel, J.; Morris, J.; Touai, H. The Economics of Battery Energy Storage; Rocky Mountain Institute: Boulder, CO, USA, 2015.

12. Sioshansi, R.; Denholm, P.; Jenkin, T.; Weiss, J. Estimating the value of electricity storage in PJM: Arbitrage and some welfare effects. Energy Econ. 2009, 31, 269-277. [CrossRef]

13. Graves, F.; Jenkin, T.; Murphy, D. Opportunities for Electricity Storage in Deregulating Markets. Electr. J. 1999, 12, 46-56. [CrossRef]

14. Teleke, S.; Baran, M.E.; Huang, A.Q.; Bhattacharya, S.; Anderson, L. Control strategies for battery energy storage for wind farm dispatching. IEEE Trans. Energy Convers. 2009, 24, 725-732. [CrossRef]

15. Teleke, S.; Baran, M.E.; Bhattacharya, S.; Huang, A.Q. Optimal control of battery energy storage for wind farm dispatching. IEEE Trans. Energy Convers. 2010, 25, 787-794. [CrossRef] 
16. Li, Q.; Choi, S.S.; Yuan, Y.; Yao, D.L. On the determination of battery energy storage capacity and short-term power dispatch of a wind farm. IEEE Trans. Sustain. Energy 2011, 2, 148-158. [CrossRef]

17. Yao, D.L.; Choi, S.S.; Tseng, K.J.; Lie, T.T. A statistical approach to the design of a dispatchable wind power-battery energy storage system. IEEE Trans. Energy Convers. 2009, 24, 916-925. [CrossRef]

18. Yao, D.L.; Choi, S.S.; Tseng, K.J.; Lie, T.T. Determination of short-term power dispatch schedule for a wind farm incorporated with dual-battery energy storage scheme. IEEE Trans. Sustain. Energy 2012, 3, 74-84. [CrossRef]

19. Yuan, Y.; Zhang, X.S.; Ju, P.; Qian, K.J.; Fu, Z.X. Applications of battery energy storage system for wind power dispatchability purpose. Electr. Power Syst. Res. 2012, 93, 54-60. [CrossRef]

20. Zhang, C.; Yang, T. Optimal maintenance planning and resource allocation for wind farms based on non-dominated sorting genetic algorithm-II. Renew. Energy 2021, 164, 1540-1549. [CrossRef]

21. Dixon, J.; Bukhsh, W.; Edmunds, C.; Bell, K. Scheduling electric vehicle charging to minimize carbon emissions and wind curtailment. Renew. Energy 2020, 161, 1072-1091. [CrossRef]

22. Emara, D.; Ezzat, M.; Abdelaziz, A.Y.; Mahmoud, K.; Lehtonen, M.; Darwish, M.M.F. Novel Control Strategy for Enhancing Microgrid Operation Connected to Photovoltaic Generation and Energy Storage Systems. Electronics 2021, 10, 1261. [CrossRef]

23. Mostafa, M.H.; Aleem, S.H.E.A.; Ali, S.G.; Ali, Z.M.; Abdelaziz, A.Y. Techno-Economic Assessment of Energy Storage Systems using Annualized Life Cycle Cost of Storage (LCCOS) and Levelized Cost of Energy (LCOE) Metrics. J. Energy Storage 2020, 29, 101345. [CrossRef]

24. Mostafa, M.H.; Aleem, S.H.E.A.; Ali, S.G.; Abdelaziz, A.Y.; Ribeiro, P.F.; Ali, Z.M. Robust Energy Management and Economic Analysis of Microgrids Considering Different Battery Characteristics. IEEE Access 2020, 8, 54751-54775. [CrossRef]

25. Abdelaziz, A.Y.; Ezzat, M.; Othman, M.M.; Mahmoud, A.M. Optimal Planning and Operation of Energy Storage Systems for Minimizing Cost of Energy Losses and Maximizing Arbitrage Benefit in Presence of Wind Generation. Electr. Power Compon. Syst. 2018, 46, 716-727. [CrossRef]

26. Fathy, A.; Abdelaziz, A.Y. Grey Wolf Optimizer for Optimal Sizing and Siting of Energy Storage System in Electric Distribution Network. Electr. Power Compon. Syst. J. 2017, 45, 601-614. [CrossRef]

27. Dhiman, H.S.; Deb, D.; Muyeen, S.M.; Abraham, A. Machine intelligent forecasting based penalty cost minimization in hybrid wind-battery farms. Int. Trans. Electr. Energy Syst. 2021, 31, e13010. [CrossRef]

28. Dhiman, H.S.; Deb, D.; Muyeen, S.M.; Kamwa, I. Wind Turbine Gearbox Anomaly Detection based on Adaptive Threshold and Twin Support Vector Machines. IEEE Trans. Energy Convers. 2021, 36, 3462-3469. [CrossRef]

29. Dhiman, H.S.; Deb, D. Wake management based life enhancement of battery energy storage system for hybrid wind farms. Renew. Sustain. Energy Rev. 2020, 130, 109912. [CrossRef]

30. Dhiman, H.S.; Deb, D. Fuzzy TOPSIS and fuzzy COPRAS based multi-criteria decision making for hybrid wind farms. Energy 2020, 202, 117755. [CrossRef]

31. Dhiman, H.S.; Deb, D.; Guerrero, J.M. Hybrid machine intelligent SVR variants for wind forecasting and ramp events. Renew. Sustain. Energy Rev. 2019, 108, 369-379. [CrossRef]

32. Rajesh, P.; Naveen, C.; Venkatesan, A.K.; Shajin, F.H. An optimization technique for battery energy storage with wind turbine generator integration in unbalanced radial distribution network. J. Energy Storage 2021, 43, 103160. [CrossRef]

33. Rayit, N.S.; Chowdhury, J.I.; Balta-Ozkan, N. Techno-economic optimisation of battery storage for grid-level energy services using curtailed energy from wind. J. Energy Storage 2021, 39, 102641. [CrossRef]

34. Fan, F.; Xu, H.; Kockar, I. Utilisation of Energy Storage to Improve Distributed Generation Connections and Network Operation on Shetland Islands. In Proceedings of the 25th International Conference on Electricity Distribution, Madrid, Spain, 3-6 June 2019.

35. Fan, F.; Zorzi, G.; Campos-Gaona, D.; Burt, G.; Anaya-Lara, O.; Nwobu, J.; Madariaga, A. Sizing and Coordination Strategies of Battery Energy Storage System Co-Located with Wind Farm: The UK Perspective. Energies 2021, 14, 1439. [CrossRef]

36. Sidorov, D.; Muftahov, I.; Tomin, N.; Karamov, D.; Panasetsky, D.; Dreglea, A.; Liu, F.; Foley, A. A Dynamic Analysis of Energy Storage with Renewable and Diesel Generation Using Volterra Equations. IEEE Trans. Ind. Inform. 2020, 16, 3451-3459. [CrossRef]

37. Nikolovski, S.; Baghaee, H.R.; Mlakić, D. ANFIS-Based Peak Power Shaving/Curtailment in Microgrids Including PV Units and BESSs. Energies 2018, 11, 2953. [CrossRef]

38. Knežević, G.; Topić, D.; Jurić, M.; Nikolovski, S. Joint market bid of a hydroelectric system and wind parks. Comput. Electr. Eng. 2019, 74, 138-148. [CrossRef]

39. Zhang, X.; Yuan, Y.; Hua, L.; Cao, Y.; Qian, K. On Generation Schedule Tracking of Wind Farms with Battery Energy Storage Systems. IEEE Trans. Sustain. Energy 2017, 8, 341-353. [CrossRef]

40. Sarojini, R.K.; Kaliannan, P.; Teekaraman, Y.; Nikolovski, S.; Baghaee, H.R. An Enhanced Emulated Inertia Control for GridConnected PV Systems with HESS in a Weak Grid. Energies 2021, 14, 172. [CrossRef]

41. Tariff Structure of Ethiopian Energy Authority. Available online: https://www.eea.gov.et/directive/economy-2018 (accessed on 14 September 2021). 